\title{
How safe was the "Safe Haven"? Financial market liquidity during the 1998 turbulences Christian Upper, Deutsche Bundesbank ${ }^{1}$
}

\begin{abstract}
Summary
The turbulences in the international financial markets during the summer and autumn of 1998 put the price formation and liquidity provision mechanism in many markets under severe strain. As part of the large-scale portfolio rebalancing that took place, investors shifted a large part of their holdings into cash and into instruments that were perceived as having a low risk and being highly liquid. One of these "safe havens" was the market for German government securities. The paper examines the liquidity of the secondary market for four German benchmark government bonds during this period. The analysis is based on a unique dataset provided by the German securities' regulator, which covers every single transaction of the four bonds in Germany. This feature is particularly attractive for the bond market, where OTC transactions account for most trading.
\end{abstract}

The volatility of yields of the four bonds more than doubled in the wake of the Russian devaluation on 17 August 1998, and experienced a further peak in early October. It was accompanied by a widening in the yield spread between the individual bonds, which soared to more than twenty basis points from less than five basis points during the first half of the year. The cost of trading, as measured by the effective spread, increased even in a "safe" haven like the market for ten year German government bonds, indicating a reduction in liquidity. Nevertheless, the market was able to handle a statistically significantly higher than usual number of transactions and turnover. In this sense, liquidity provision has been remarkably effective in dealing with the turbulences.

Effective bid-ask spreads are positively related to unexpected trading volume, which should reflect the amount of private information in the market. Nevertheless, surprises volume cannot explain the surge in spreads that occurred during the turbulences.

\section{Introduction}

The turbulences in the international financial markets during the summer and autumn of 1998 put the price formation and liquidity provision mechanism in many markets under severe strain. Both the International Monetary Fund and the Bank for International Settlements ${ }^{2}$ cite anecdotal evidence that "market liquidity dried up temporarily even in the deepest and most liquid markets as risks were repriced and positions deleveraged"(IMF [1998]). As part of the large-scale portfolio rebalancing that took place, investors shifted a large part of their holdings into cash and into instruments that were perceived as having a low risk and being highly liquid. One of these "safe havens" was the market for German government securities. The purchases of German debt securities by non-residents, which had averaged some of 11.4 billion DM per month during the first half of 1998, soared to 34.5 billion DM in July and remained close to this level in August. Most of this increase went into bonds issued by the Federal government, in particular those with maturities around ten years, whose yields fell accordingly. ${ }^{3}$ The safe-haven effect disappears from the data as the turbulences reached their climax

1 Discussion paper 1/00, Economic Research Group of the Deutsche Bundesbank. Parts of the paper have been written during a visit at the Bank of England's Financial Intermediaries Division, which I thank for its hospitality. I am particularly grateful to Charles Goodhart for helping me to arrange the visit and taking an active interest in its success. My work has benefited greatly from discussions with Torsten Arnswald, John Board, Dietrich Domanski, Heinz Herrmann, Manfred Kremer, Narayan Naik, Anthony Neuberger, Richard Payne, Victoria Saporta, Anne Vila and several staff at both the Bundesbank and the Bank of England. It would not have been possible without the generous help of Patrick Umlauf and Michael Kollak of the Bundesamt für den Wertpapierhandel, who made the data available. I would also like to thank Gerhard Klopf and Uwe Ullrich for valuable information on the institutional structure of the German bond market. All remaining errors are mine. The discussion papers published in this series represent the authors' personal opinions and do not necessarily reflect the views of the Deutsche Bundesbank.

2 IMF (1998) and BIS (1999a).

3 As a consequence, the spread between the benchmark government bonds and bonds issued by other institutions widened significantly. See Deutsche Bundesbank (1998). 
in early October. Purchases of German bonds by non-residents fell back to 8.6 billion DM in September and were actually negative in October, when foreign investors reduced their holdings of German bonds by 10 billion DM.

This paper analyses the evolution of prices and indicators for market liquidity during 1998 for four benchmark 10 year Bundesanleihen. These securities represent the most liquid and actively traded segment of the German fixed income market, and were the main beneficiary of the flight into quality. In particular, I focus on the question of how the turbulences affected market liquidity and price formation. In other words, how did the safe haven weather the storm? Beyond this immediate question, the paper intends to further our understanding of the mechanisms for the provision of liquidity in securities markets more generally, especially in periods of stress.

The market for Government debt is of particular concern to central banks for a number of reasons. ${ }^{4}$ Firstly, the prices of government securities provide important indicators for monetary policy, eg through the yield curve, and serve as benchmarks for the pricing of other securities. Such indicators will only be accurate if prices are efficient, ie if they accurately reflect all available information. If markets are not liquid enough, then this may not be the case.

Secondly, government bonds are important hedging vehicles for market participants. A breakdown in market liquidity turns tradable assets turn into non-marketable loans or at least induces large changes in prices. This can lead to substantial losses for those market participants who rely on the ability to turn over positions quickly and at a low price. Upper bounds for the cost of a temporary interruption of tradability have been derived using an options pricing approach by Longstaff (1995). Such costs arise from investors not being able to optimally time their trades. The upper bounds are concave in the time during which the asset cannot be sold, indicating that the cost of illiquidity may be very high even if the period of non-tradability lasts only a short period of time.

In addition, continuous liquidity is the key assumption of standard option pricing and risk management models, which are based on dynamic hedging strategies. If the underlying assets cannot easily be traded, then options can no longer be priced correctly and the riskiness of a portfolio cannot be assessed. While this does not directly impose a cost on investors, it contributes to a rise in uncertainty about their financial health and may trigger off massive sales or runs that could possibly call into question the stability of the financial system. The prevention of such periods of illiquidity should therefore be of serious concern to policymakers and central banks in their quest to safeguard financial stability.

A third reason for why central banks should be interested in the market for government bonds lies in their role as fiscal agents. If secondary markets are not very liquid, then this may add to the borrowing costs of the government. This cost of illiquidity can be substantial. For example, Amihud \& Mendelson (1991) find that, after accounting for brokerage fees, the yield of US-Treasury Bills was on average 39 basis points lower than that of Treasury Notes of the same residual maturity but with a bid-ask spread about four times as high. ${ }^{5}$

Market microstructure theory has identified three factors which affect liquidity in financial markets: order processing costs, inventory control considerations and adverse selection problems. ${ }^{6}$ Order processing costs include exchange fees and taxes as well as the more immediate costs of handling transactions. They should be fairly constant over time unless changes in the microstructure of the market or in technology take place, and are therefore an unlikely candidate when it comes to explaining variations in market liquidity.

Inventory and adverse selection effects are much more likely to vary even in the short run. The former arise from uncertainty about the order flow and thus the size of the inventory as well as from uncertainty about future prices and hence the valuation of the portfolio. ${ }^{7}$ Adverse selection problems arise when a group of investors has private information on the value of the asset and will want to trade

\footnotetext{
4 This has been pointed out by several papers in BIS (1999b). portfolios as a consequence of buy-and-hold strategies.

6 A survey of the theoretical literature on market microstructure is O'Hara (1995).

7 Models of inventory control include, among others, Ho \& Stoll $(1981,1983)$ and O'Hara \& Oldfield (1986).
} 
only if the current ask price is below, or the bid price above the fundamental value of the asset. In either case, the market maker would make a loss, which he has to recoup from other investors by charging a positive bid-ask spread. This idea, which goes back to Bagehot (1971), has been formalised in a dynamic setting by Glosten \& Milgrom (1985) and Kyle (1985), who analyse the pricing strategy of a risk-neutral market maker facing a sequence of informed traders (Glosten \& Milgrom) and a strategically acting information monopolist (Kyle). In their models, market liquidity is a decreasing function of the precision of private information relative to the information available to the market maker. If the degree of asymmetric information increases beyond a threshold, then market makers would have to widen their bid-ask spreads by an extent that would drive away liquidity traders (Glosten \& Milgrom) or would make prices infinitely sensitive to volume (Kyle). In either case, an equilibrium of the continuous trading involving a market maker would not exist. But even if continuous trading may not be feasible in equilibrium, Madhavan (1992) shows that it may still be possible to trade in auctions that take place at discrete time intervals over which all trades are aggregated and executed at a single price. They may even work if market makers withdraw from trading altogether.

There is by now a large literature on the importance of inventory control and adverse selection effects in the price formation process. ${ }^{8}$ However, with the exception of the work of Proudman (1995) and Vitale (1998) on the UK gilt market, so far mainly equity markets have been looked at. This may be due to the fact that data is more easily available for equities, which tend to be traded on organised exchanges, than for bonds, which are mostly traded over the counter. Also, existing models of adverse selection are based on the assumption that some investors have superior information on the payoff of the asset. This is unlikely to be the case for government bonds, where cash flows are perfectly known. Private information may nevertheless play a role in these markets since some investors may know more about short term supply and demand conditions, eg on trading strategies of institutional investors.

Proudman (1995) estimated the importance of asymmetric information in the market for UK government bonds, using the VAR approach of Hasbrouck (1991). He finds no indication for either asymmetric information or inventory control. This is partly in contrast with the results obtained by Vitale (1998), who finds that while customer orders do not seem to provide any information to market makers, this is not the case for inter-dealer transactions, which do seem to carry information. This is exactly what we would expect from the modified adverse selection story informally set out in the previous paragraph. Vitale finds no indication for inventory effects, and comes to the conclusion that the market for gilts is very deep.

Both the inventory and the adverse selection models give hints at why market liquidity may dry up, but they don't actually model this explicitely. Instead, they assume that the factors driving the degree of liquidity (volatility of the underlying price process, behaviour of noisy traders, precision of private information) are exogenous and constant over time. If we allow these factors to vary over time, possibly even endogenously, then the equilibria of the models may be different or may not even exist. There simply is, at least to my knowledge, no satisfactory theory of liquidity breakdowns. The same applies to the empirical literature, which assumes that spreads, and hence liquidity, is constant over time.

The present paper loosens this assumption and allows liquidity to vary across days, although not within a day. I find that while liquidity is relatively constant over time when markets operate in normal conditions, this is not the case during periods of stress. During the financial market turbulences of August to October, 1998, the effective bid-ask spreads in the market for German government bonds more than doubled, indicating a significant worsening of liquidity.

The paper is structured as follows: Section 2 reviews the literature on the 1998 turbulences in the international financial markets and presents a dating scheme that is used in the remainder of the paper. In the following section, I discuss the concept of market liquidity before turning to the issue of how to measure it. Section 4 gives an overview of the institutional structure of the market for Bunds and section 5 describes the data. Empirical results are presented in sections 6 and 7, which focus on yields and indicators for liquidity, respectively. A final section concludes.

8 A good example is Huang \& Stoll (1997), which also contains a comprehensive review of the literature. 


\section{The 1998 turbulences in international financial markets}

In the summer and autumn of 1998, many international financial markets experienced a period of severe stress which provoked fear of a worldwide recession and deflation. Asset prices became very volatile, the bid-ask spreads in many, but not all, markets increased dramatically, and hitherto stable pricing relationships between different assets broke down. ${ }^{9}$ Episodes of collapsing liquidity in securities markets are nothing new, but few if any have affected markets as important as the US bond market or the dollar-yen market. ${ }^{10}$

This section gives a brief outline of the events associated with the turbulences. It is largely based on the report of the Committee on the Global Financial System (BIS [1999c]), whose narrative-historic dating scheme, which informally draws on a large number of statistics, is presented in Table 1.

While it is tempting to date back the start of turbulences in the international financial markets to the Thai devaluation in July 1997, it was not until after the Russian default on 17 August 1998 that the turbulences spread to the markets of the developing economies. But even before, in July and the first half of August, there had been signs that strategies of relative value arbitrage, which involve buying an asset that is perceived to be undervalued and simultaneously selling a similar asset that is expected to fall in price, had led to losses at several large investors. Consequently, the BIS dating begins with a period of mounting tensions, ranging from 6 July to 14 August. Nevertheless, asset price and exchange rate volatility as well as bid-ask spreads were relatively low during this subperiod.

The Russian devaluation and effective default on its short term debt on 17 August caused sizeable losses to some investors and led to a general deleveraging of positions. This affected primarily the yield spreads of non-benchmark securities relative to the benchmarks and, to a lesser extend, price volatility and bid-ask spreads. The recapitalization of LTCM, a large hedge fund, on 23 September, marked the beginning of the third, most turbulent, subperiod, where yield spreads, volatility and bidask spreads soared to record levels. The turbulences began to subside after the inter-meeting rate cut by the Federal Reserve on 15 October, which marks the beginning of the fourth and final period, although yield spreads, volatility and bid-ask spreads remained high until the end of the year.

Table 1

The 1998 Financial Market Turbulences

\begin{tabular}{|c|c|c|}
\hline & Dates & Events \\
\hline I. & 6 July - 14 Aug & $\begin{array}{l}6 \text { July: Salomon Brothers arbitrage desk disbanded } \\
20 \text { July: First Wall Street Journal on LTCM losses } \\
23 \text { July: Japanese sovereign debt placed under review }\end{array}$ \\
\hline II. & 17 Aug - 22 Sept & $\begin{array}{l}17 \text { Aug: Russian effective default and rouble devaluation } \\
2 \text { Sept: LTCM shareholder letter issued }\end{array}$ \\
\hline III. & 23 Sept - 15 Oct & $\begin{array}{l}23 \text { Sept: LTCM recapitalisation } \\
29 \text { Sept: Federal Reserve interest rate cut } \\
\text { early Oct: Interest rate cuts in Spain, UK, Portugal and Ireland } \\
7 / 8 \text { Oct: Large appreciation of Yen relative to US dollar related to closing of "yen carry trades" } \\
12 \text { Oct: Japanese Diet approves bank reform legislation } \\
14 \text { Oct: BankAmerica reports } 78 \% \text { fall in earnings } \\
15 \text { Oct: Federal Reserve cuts rate between meetings }\end{array}$ \\
\hline IV. & 16 Oct - 31 Dec & $\begin{array}{l}5 \text { Nov: Bank of England cuts rates } \\
13 \text { Nov: Brazil formally requests IMF programme } \\
17 \text { Nov: Federal Reserve cuts rates, Japanese sovereign debt downgraded } \\
2 \text { Dec: IMF Board approves programme for Brazil } \\
3 \text { Dec: Coordinated rate cut by European central banks } \\
10 \text { Dec: Bank of England cuts rates }\end{array}$ \\
\hline
\end{tabular}

Source: BIS (1999c).

9 See data appendix of BIS (1999c) for details.

10 Davies (1999) compares the 1998 turbulences to previous episodes. 


\section{Liquidity measurement}

\subsection{The four dimensions of market liquidity}

The liquidity of a secondary market refers to the "ease" with which securities can be traded. As is so often the case, liquidity is in general easy to recognise but difficult to define. Four dimensions of liquidity have been mentioned in the literature: tightness, depth, resiliency and immediacy.

A market is tight if there are enough limit orders or quotes in the vicinity of the last trading price such that new buy and sell orders can be executed without great discontinuities in prices. Tightness is directly measured by the bid-ask spread, which in Figure 1 corresponds to the vertical distance between the lowest ask and the highest bid prices. A market is deep if large orders can be executed without much effect on prices. In Figure 1, market depth is given by order size, measured on the horizontal axis, and the relevant spread for that amount, measured on the vertical axis.

Figure 1

\section{Dimensions of market liquidity}

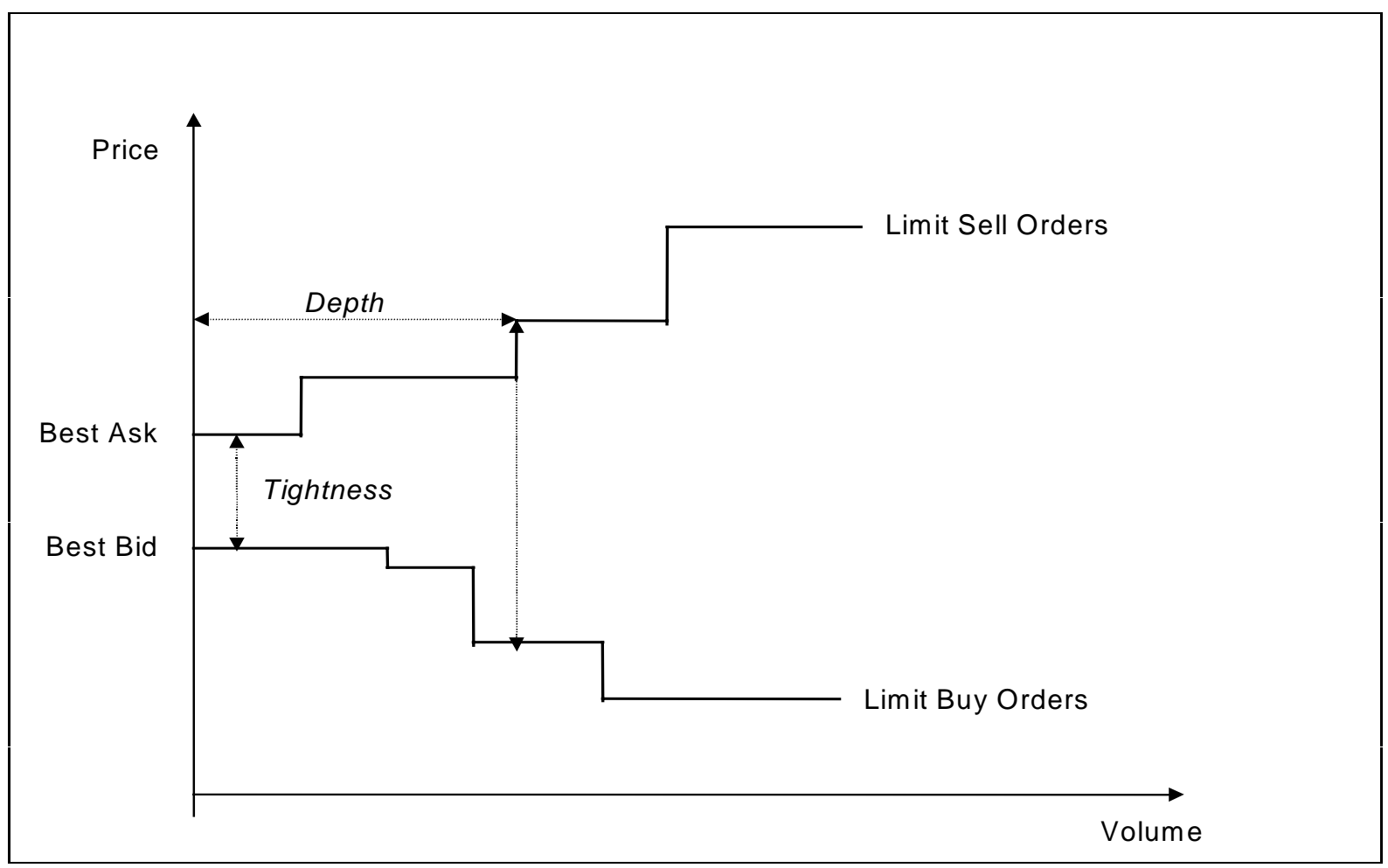

Both tightness and depth are essentially static concepts, which describe a market at a given point in time. This is in contrast with the concept of resiliency, which describes the speed at which price movements due to temporary imbalances between buy and sell orders attract new orders which drive the price back to the fundamentally justified level. This is important because large orders are often split into several small orders which are executed sequentially. In a resilient market, an investor doing this would nevertheless obtain a price which, in the absence of any news, would on average be close to the current market price. In Figure 1, resiliency refers to the speed with which the bid and the ask schedules move back to their initial positions after an order has been executed.

The final dimension of liquidity is immediacy, which refers to the time that passes between the placing of a market order and its execution. This seems to have been a problem on the New York Stock Exchange during the stock market crash of October 1987, when orders had to wait up to 75 minutes 
for execution, apparently due to long printing queues. ${ }^{11}$ Unfortunately, immediacy cannot be tested with transactions or quote data, since the time when an order was submitted is not known.

\subsection{Measures for market liquidity}

Market liquidity has traditionally been proxied by indicators for market activity like the number of trades, trading volume or the spacing between trades. ${ }^{12}$ These measures have the advantage that they are immediately available or at least easy to compute, but unfortunately are not directly related to any of the four dimensions of liquidity presented in the previous subsection. Market liquidity is only one, and not necessarily the most important, factor affecting trading activity. For example, if traders have sufficiently large hedging needs, then they may trade even if market liquidity, in terms of tightness, depth, resiliency and immediacy, is relatively low.

Nevertheless, even though there is not a one to one relationship between trading activity and liquidity, indicators such as turnover or the intervals between trades do show that markets are sufficiently liquid to sustain a given amount of trading. The converse is not the case, however. The absence of transactions does not necessarily imply that markets are not liquid but may be due to the agents not wanting to trade at the market clearing prices. Such no-trade equilibria are common in theoretical models with homogenous agents. So, while we should not discard activity indicators altogether, it would be preferable to have measures that are linked to at least one of the four dimensions of market liquidity.

A measure for liquidity that is both easily available and in line with one of the four dimensions mentioned before is the quoted bid-ask spread, which indicates the tightness of a market. In quotedriven markets such as the over-the-counter market for German government bonds quoted spreads can be observed by traders at any point in time. ${ }^{13}$ Unfortunately, quoted spreads may not represent the true cost of trading since many transactions take place at prices inside the quoted bid-ask bracket. In addition, they apply to transactions up to a specified amount only, which, furthermore, varies over time. E.g., if market participants cut this amount in periods of stress, then this would leave the quoted spread unchanged.

We can overcome the problems associated with quoted spreads by computing effective spreads. In contrast to the former, effective spreads refer to the average transaction and thus captures not only the tightness but also the depth of a market. They are computed from transactions data and thus reflect the price actually paid by traders and not the price announced by dealers.

The computation of the effective spread goes back to the seminal work of Roll (1984), who uses the negative first order autocorrelation in transaction prices that results from transactions being undertaken alternately at bid and ask prices. Assuming that buy and sell orders arrive with equal probability and that the bid-ask spread effectively paid by the traders remains constant over the estimation period, he shows that the spread is given by

$s=2 \sqrt{-\operatorname{Cov}\left(\Delta P_{t}, \Delta P_{t-1}\right)}$

Unfortunately, there are a number of problems associated with the Roll measure. First of all, as is shown in Stoll (1989), in the presence of adverse selection or inventory effects it may underestimate the actual spread. Secondly, a bias may be induced by the fact that the number of bid and offer transactions may not be balanced. ${ }^{14}$ Nevertheless, its simplicity and the ease with which it is

\footnotetext{
11 Brady (1989).

12 For examples, see BIS (1999b).

13 Since there is no commitment to market making in the OTC market for Bundesanleihen, quoted spreads are merely indicative, ie agents do not have to honour the prices they promise. While this should not matter in normal times, it may be a problem in periods of stress.

14 See Choi et al (1988) on how to adjust Roll's estimator for this.
} 
implemented make the Roll measure a good starting point when measuring liquidity, although its limitations have to be borne in mind. ${ }^{15}$

More recently, several other ways for computing spreads from transactions data have been developed. ${ }^{16}$ Their computation is more involved than that of the Roll measure, which is why they have not been included in this paper.

\section{The market for German government bonds ${ }^{17}$}

This section describes the trading arrangements in the market for German government bonds. As is generally the case in the microstructure literature, the institutional structure of a market is of great importance since it conditions the availability of data and is important for the interpretation of the results. A description of the structure of the market for German government securities is also of interest in its own right, since it differs from that of other securities markets.

The market for German 10 year Bundesanleihen (Bunds) represents the most liquid segment of the European bond market and provides a benchmark for the pricing of long maturity bonds throughout Europe. German government bonds are traded both on organised exchanges and over the counter (OTC), with the latter accounting for the bulk of trading. This is especially true for the inter-dealer market, where trading takes place either directly between banks or through inter-dealer brokers (Freimakler). These act as intermediaries, but have no obligation to provide firm quotes. While the academic literature would suggest that dealers use brokers mainly in order to obtain anonymity, ${ }^{18}$ conversations with market participants have hinted at a more mundane reason: Brokers seem to be more efficient in matching counterparties because of their more active participation in the market.

While there is a trend towards electronic trading, this stage had not yet been reached during 1998, when brokers posted their quotes on screen but the actual transactions took place over the phone. Electronic trading is more important in the client market. Large banks run proprietary trading systems, where they provide quotes for their customers. Recently, electronic trading systems as the Euro-MTS have become more important also in the inter-dealer market, but in 1998 their role was negligible.

The OTC market seems to be rather opaque. Participants observe quotes but do not receive timely information on other traders' past transactions beyond anecdotal evidence. In principle, it would be possible to obtain this information from clearing data, but it would arrive with a delay of up to three days and would be expensive to collect.

The role of exchanges is minor in comparison to the OTC market, even though all issues are listed. Trading takes place almost exclusively on the Frankfurt Stock Exchange, the role of regional exchanges is negligible. In 1998, German government bonds traded more or less entirely by open outcry since the computerised trading system XETRA did not permit traders to link their quotes to the price of the Bund future. ${ }^{19}$ Prices are formed by a specialist broker (Kursmakler), who has to ensure price continuity. If the potential market clearing price lies outside a pre-specified corridor, he interrupts trading for five minutes and calls for new quotes. He may undertake some trading on his own account,

15 Two practical difficulties may arise when implementing Roll's method. Firstly, the estimate for $\operatorname{Cov}\left(\Delta P_{t}, \Delta P_{t-1}\right)$ may be negative. In this case, I drop the observation from the sample. Secondly, the fact that the autocovariance of prices is not known but has to be estimated from the data induces a small sample bias. This can become a problem when estimating the effective spread over short time intervals like individual days. However, Roll (1984) argues that the bias is relatively small, eg for a sample of 60 observations it would amount to about two percent of the spread, which would seem acceptable. I deal with the problem dropping all intervals with less than 50 observations.

16

They are surveyed in Huang \& Stoll (1997), who also present their own measure for estimating and decomposing the spread into the components due to order-processing, inventory control and adverse selection costs.

17

The description of the market for Bunds draws from conversations with Gerhard Klopf and Uwe Ullrich, of the trading desks of the Bundesbank and Deutsche Bank, respectively. I focus the market for Bunds as it was in 1998 and ignore many recent developments.

18 At least temporarily, as the banks receive details on their counterparty for clearing purposes. Only very recently did brokers act as a counterparty, thus preserving anonymity even after clearing.

19 This possibility has been provided in the summer of 1999, but it remains to be seen whether this will shift more activity onto XETRA. 
but this occurs mainly to offset imbalances in order size and does not seem to play a big role in providing market liquidity.

\section{Data}

\subsection{Description}

The data covers all transactions in Germany during 1998 of four government bonds (Bunds) with a residual maturity of 8 to 10 years. It includes all Bundesanleihen (long term bonds issued by the federal government) with an original maturity of 10 years that were issued between January 1997 and July 1998. Details on the individual bonds are given in Table 2. The securities have been selected because they were delivered for the Eurex Bund future in 1998.

Bundesanleihen are usually first issued in January and July, and the size of the issue is increased during the following months. The autumn of 1998 marked an exception to this rule, as in the wake of falling interest rates a new issue with a lower coupon was brought to the market outside the normal issuing schedule in November. As a consequence, the 4.75\% bond first issued in July 1998 has a volume outstanding of only 17 billion DM compared to 30 billion DM for the other three bonds in our sample.

The data has been provided by the German securities' regulator Bundesaufsichtsamt für den Wertpapierhandel (BAWe), which receives notice of every single transaction in Germany, irrespective of whether or not it takes place on an exchange. This feature is particularly attractive for work on the bond market, where OTC transactions account for most trading.

Bunds are also traded abroad, in particular in London. Unfortunately, we do not have any information on transactions outside Germany, although there is anecdotal evidence that the market share of London has fallen in recent years, albeit by a lesser extent than the one in the market for Bund futures.

In principle, we should have two observations for each trade: one concerning the final buyer and another for the final seller of the security. An exception are trades with intermediaries that reside outside Germany and are therefore not subject to the reporting requirement. For each observation, we have a date and time stamp, price, volume, as well as indicators for whether it is the sale or the purchase leg of a transaction, whether the reporting bank's inventory is affected, whether the reporting bank acts as an agent for a customer or on its own account, and whether trade takes place over the counter or on an exchange.

Some observations on the quality of the data are in order. Firstly, the precision of the time stamps (up to the nearest second) may be more apparent than real. It is probably high for trades that take place on an exchange, but may be low for OTC-transactions. An indication for this is that many trades are reported as taking place outside normal office hours, often at midnight sharp or at prices that seem out of date. Inaccurate time stamps represent a severe problem since the reliability of most indicators for liquidity crucially depend on the correct sequence, although not so much the timing, of trades. Secondly, other variables may have been reported incorrectly. While most of such errors have been eliminated by the BAWe using supplementary information, some mistakes especially in prices or volume may remain.

Matching the buy and sell legs of transactions and filtering the data can reduce the severeness of these problems. Unfortunately, matching the two legs is not straightforward, in part because of errors in the data and in part because of missing notifications. I have matched all purchases and sales that occurred on the same day at the same price and with the same volume. If the time stamps of these pairs of "matched" observations do not coincide, I have used the earlier one. Of a total of 145 thousand observations in our raw data, only about half could be matched in this way. ${ }^{20}$ Since the remaining "unmatched" observations account for a large proportion of market activity, I have decided to keep them in the data. After matching, we are left with 109 thousand observations, which further

20 The BAWe successfully matches the various notices for more than three quarters of the trades but uses supplemental data to achieve this. They use the matches in order to hunt down missing notifications and to eliminate contra-trades. Since the matches are stored in a different database, using this information in the present study would have incurred computational costs that seemed out of proportion to the limited benefits of doing so. 
reduce to 99 thousand after filtering. ${ }^{21}$ Of these, 66 thousand, $2 / 3$ of the total, were not due to matches (see Table 2).

\begin{tabular}{|c|c|c|c|c|}
\hline \multicolumn{5}{|c|}{$\begin{array}{c}\text { Table } 2 \\
\text { Summary statistics }^{1}\end{array}$} \\
\hline $\begin{array}{l}\text { Coupon } \\
\text { Maturity } \\
\text { Volume outstanding (in billion DM) } \\
\text { Number of trades } \\
-\quad \text { unmatched } \\
-\quad \text { matched } \\
-\quad \text { matched and filtered } \\
\text { of which not due to matches } \\
\text { Client trades } \\
\text { Sales } \\
\text { Purchases } \\
\text { Could not be attributed } \\
\text { Inter-dealer trades } \\
\text { 3 } \\
\text { Total volume (DM billion) } \\
\text { Client trades } \\
\text { Inter-dealer trades } \\
\text { Average trade size (DM million) } \\
\text { Client trades }{ }^{3} \\
\text { Purchases } \\
\text { Sales } \\
\text { Not attributable } \\
\text { Inter-dealer trades }\end{array}$ & $\begin{array}{r}6 \% \\
04.01 .07 \\
30 \\
\\
21,366 \\
16,608 \\
14,799 \\
10,490 \\
2,186 \\
548 \\
534 \\
1,104 \\
2,123 \\
273.2 \\
64.7 \\
25.9 \\
18.5 \\
29.6 \\
17.7 \\
19.6 \\
43.5 \\
12.2\end{array}$ & $\begin{array}{r}6 \% \\
04.07 .07 \\
30 \\
33,616 \\
22,832 \\
22,407 \\
14,247 \\
2,966 \\
806 \\
794 \\
1,366 \\
5,194 \\
486.2 \\
113.9 \\
57.0 \\
21.7 \\
38.4 \\
22.6 \\
21.4 \\
58.9 \\
11.0\end{array}$ & $\begin{array}{r}5,25 \% \\
04.01 .08 \\
30 \\
64,594 \\
48,191 \\
44,216 \\
29,018 \\
5,678 \\
1,663 \\
2,010 \\
2,005 \\
9,520 \\
780.4 \\
159.7 \\
99.6 \\
17.6 \\
28.1 \\
15.5 \\
15.1 \\
54.5 \\
10.5\end{array}$ & $\begin{array}{r}4.75 \% \\
04.07 .08 \\
17^{2} \\
25,586 \\
19,551 \\
17,679 \\
12,198 \\
2,283 \\
827 \\
618 \\
838 \\
3,198 \\
281.1 \\
54.1 \\
41.9 \\
15.9 \\
23.7 \\
16.8 \\
14.1 \\
38.3 \\
13.1\end{array}$ \\
\hline
\end{tabular}

Of the 99 thousand observations of our matched and filtered sample, 44 thousand, or just under half, are for the $5.25 \%$ bond due in January 2008, which was on-the-run (ie the most recent issue) during the first half of 1998 . There are far less transactions for the two $6 \%$ bonds, with 15 and 22 thousand trades, respectively. The $4.75 \%$ bond issued in July 1998, which was on the run between July and November, when a new Bundesanleihe not included in our sample was issued, was traded 18 thousand times.

As was mentioned before, our dataset contains information on whether the sale or purchase leg was an agency trade or on the intermediary's own account. In the case of "matched" observations, this allows us to distinguish inter-dealer trades, where banks appear on both sides, from client trades, which cover the remainder. A transaction is classified as a client sale (purchase) if the sale (purchase) involved a client and the counterparty was a bank. If both the purchase and the sale are agency trades, then the transaction is counted as non-attributable client trades. Unfortunately, this classification is not possible for "unmatched" trades.

Client trades account for less than $40 \%$ of the "matched" transactions, and inter-dealer trades for the remainder. Of the former, about $30 \%$ were identified as purchases and approximately the same number as sales, the remaining client transactions could not be attributed.

21 I have deleted all observations that are reported to take place either before 8:00 or after 18:00 and those with prices outside a bracket of three standard deviations around a second order polynomial fitted to the prices of all transactions that occur during the same day. While the deletion of observations necessarily leads to a loss in information, I believe that this is much less severe than the problems associated with wrong time stamps or outliers in prices. 
Figure 2(a)

\section{Distribution of trade size}

(all trades)
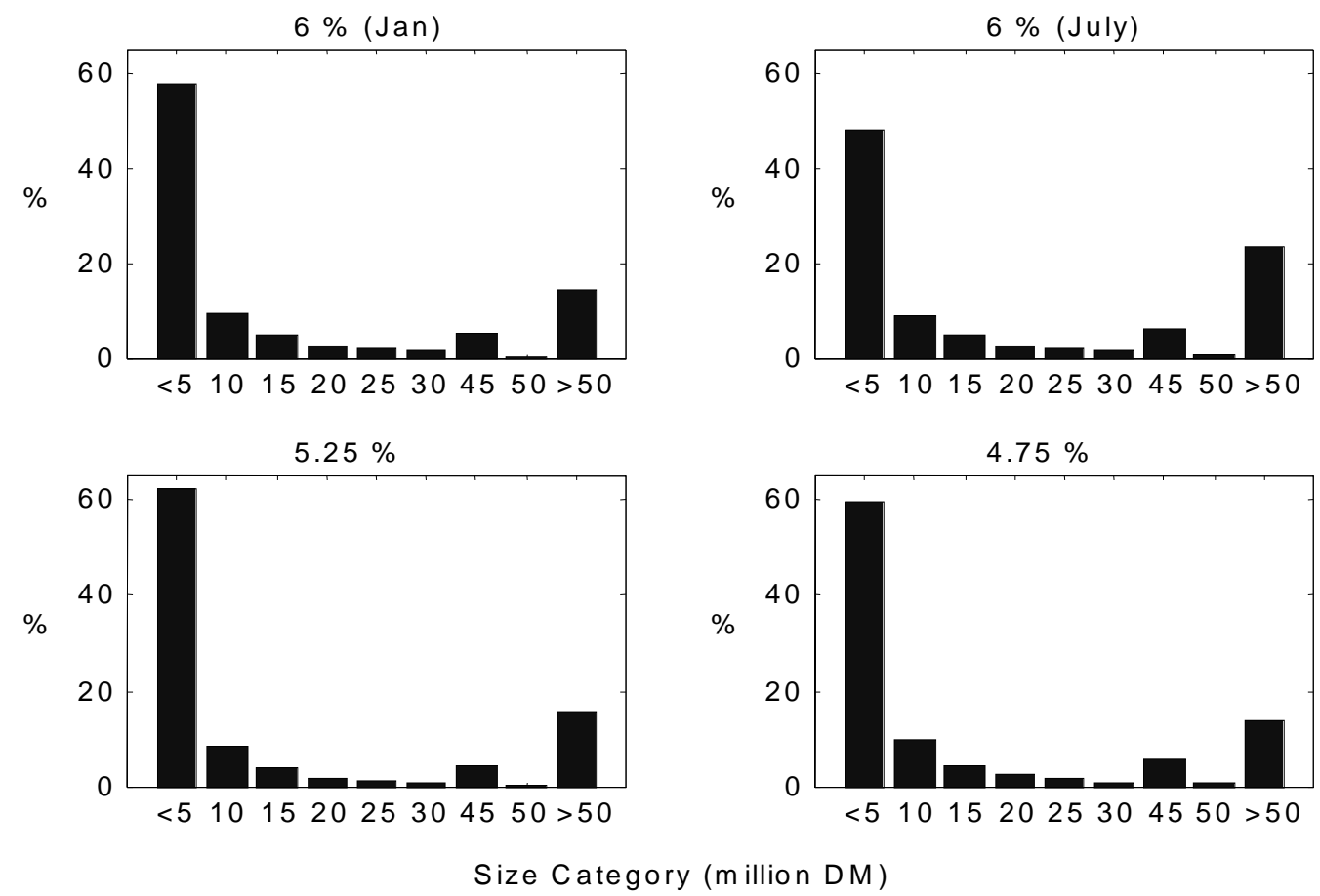

The distribution of trade sizes of all transactions is shown in Figure 2(a). Small trades of up to 5 million DM accounted for around one half of all transactions and large trades above 50 million DM for a further tenth to one fifth. These aggregate figures mask important differences between the different types of transactions, as can be seen from Figure 2(b). Inter-dealer Trades are much more likely to be small than client transactions, where about one third of all trades tops 50 million DM. As a consequence, the average trade size was considerably larger for client trades than for inter-dealer transactions for all four bonds. This gap exists for all three classes of client transactions (sales, purchases and not attributable), although it is by far largest for trades which involve clients on both sides. 
Figure 2(b)

\section{Distribution of trade size}

(client and inter-dealer trades)
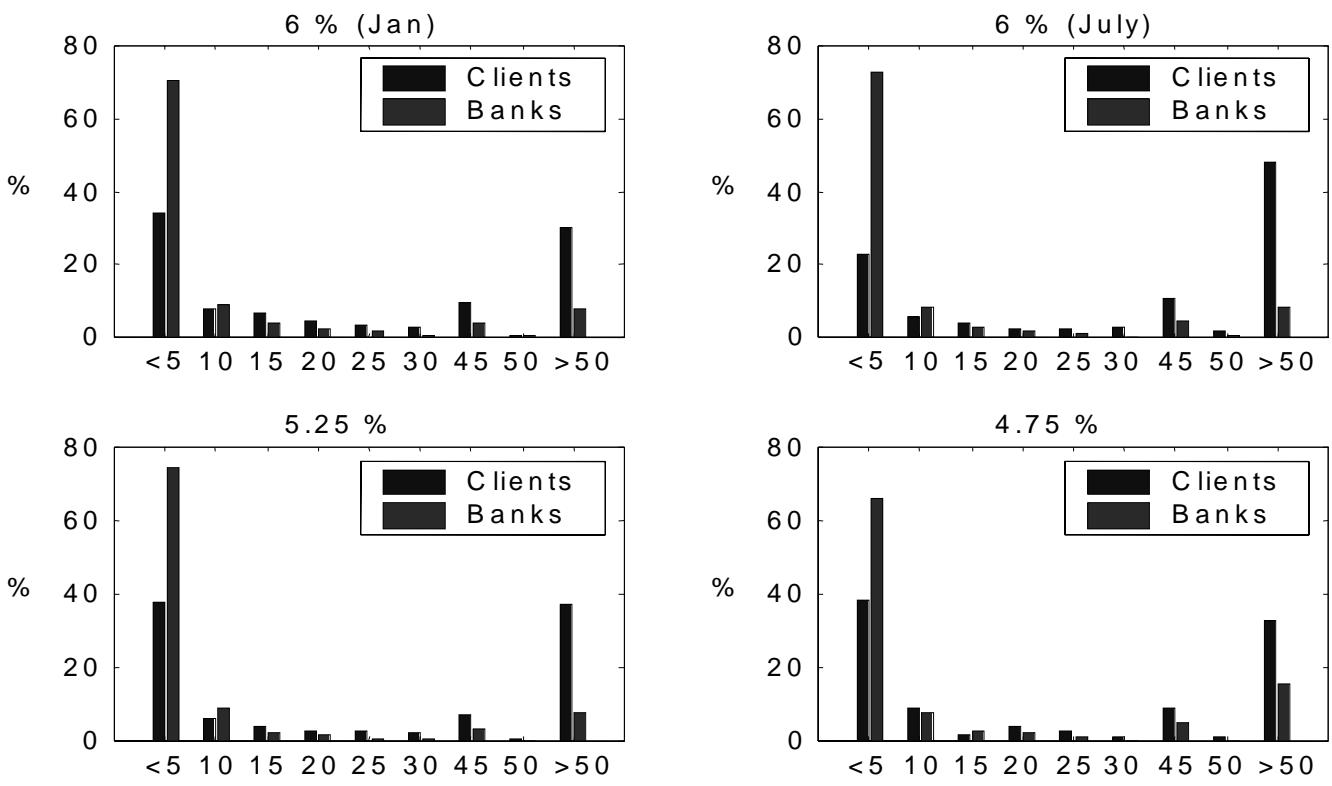

Size Category (m illion DM)

Our data also contains information on whether or not a trade affected the reporting bank's inventory, which permits us to construct a series for the aggregate inventory of the banking sector at any given point in time by simply adding up all transactions which affect inventories, and assuming that the inventory at the beginning of the year was zero. In the case of the two $6 \%$ bonds, this latter assumption is arbitrary, the inventory series for these bonds can therefore only be interpreted in terms of movement over time but not in terms of the actual level of inventory.

Figure 3 shows the inventories at the end of each trading day for the four bonds. ${ }^{22}$ They tend to fluctuate within a relatively narrow band around zero. On more than $50 \%$ of all days, they are between -10 and +10 million DM, which is considerably less than the average transaction size, and exceed 100 million or are below -100 million on only $5 \%$ of trading days.

According to our figures, between $78 \%$ and $86 \%$ of all trades took place over the counter, ${ }^{23}$ although this may understate the true figure as many OTC-transactions after execution are entered into an exchange's trading system in order to take advantage of the automated clearing facilities, and reporting banks may "forget" to enter the variable correctly.

22 End-of-day inventories have been computed from the unfiltered data, since dropping any transaction would reduce the reliability of the data. In addition, misreported time stamps or prices do not have any effects on the quality of the series.

Trades are counted as OTC if identified by the börslich-flag or if recorded before 8:00 or after 18:00 hours. 
Figure 3

End-of-day inventories
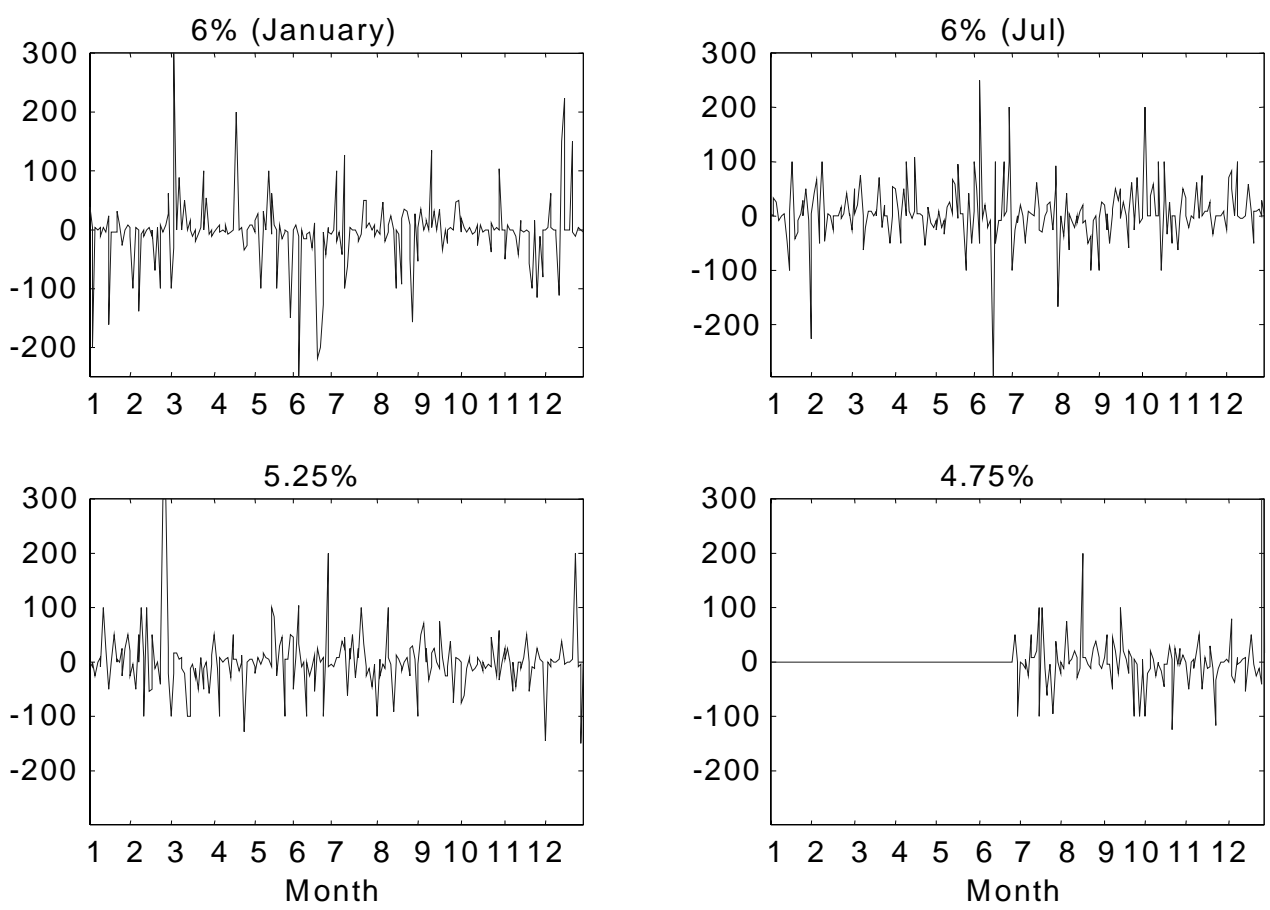

In million DM

\subsection{Intra-day patterns of trading activity}

Trading activity is very unevenly distributed over the trading day, as can be seen from figures 4(a) (c), which plot the distribution of the number of trades, turnover and average trade sizes within half hourly intervals. Trading activity shows two peaks during the day. The first peak occurs in the morning between 9:30 to 10:00, when around 10\% of all trades take place, which however account for a much higher share of daily turnover. The average trade size in this half hour period is consequently more than twice as high as during the remainder of the day. The second peak in activity occurs between $11: 30$ and $12: 00$, when between $12 \%$ to more than $20 \%$ of all trades take place. These tend to be small trades, however, with an average trade size below that of any other interval. Trading is least heavy in the early morning, before 8:30, at lunchtime between 13:00 to 14:00, and in the evening after 17:00. 
Figure 4 (a)

Intra-day distribution of number of trades
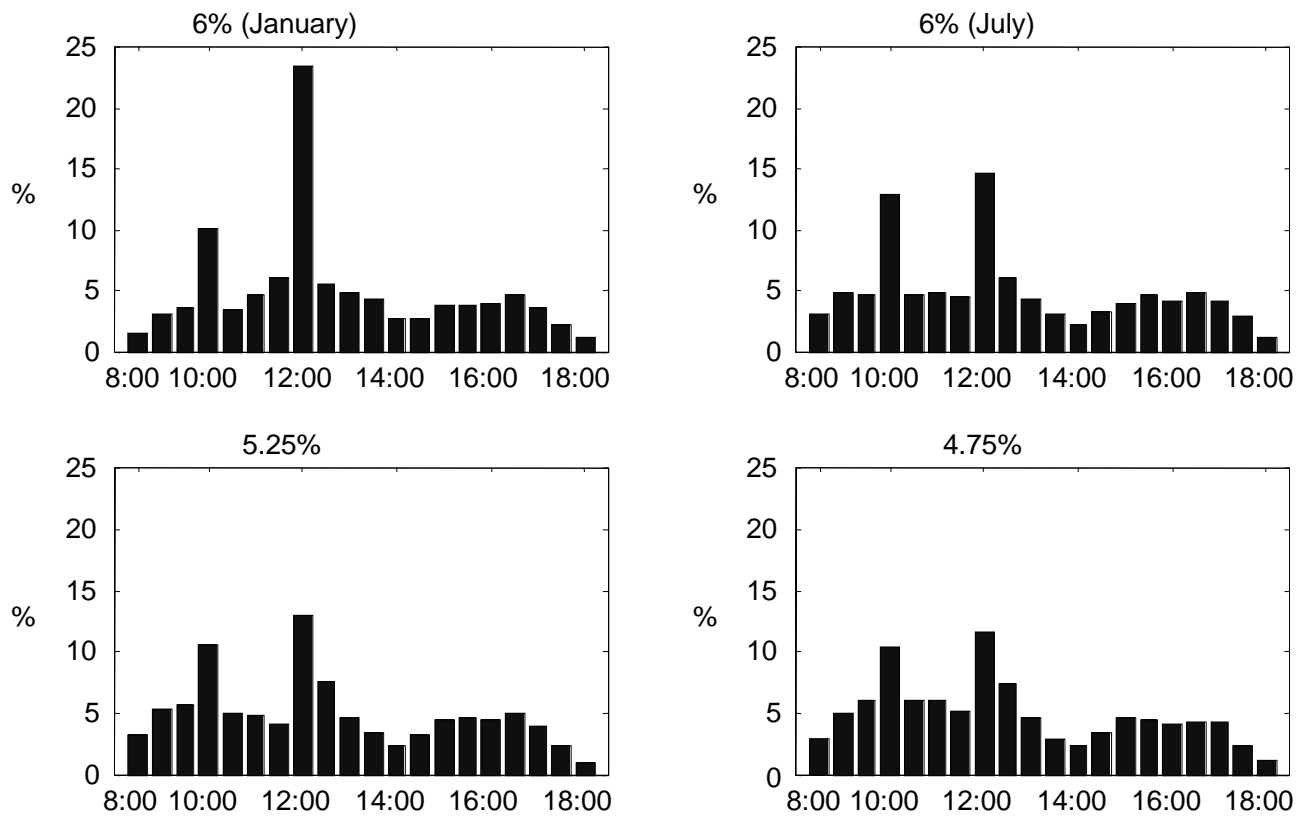

Figure 4 (b)

Intra-day distribution of trading volume
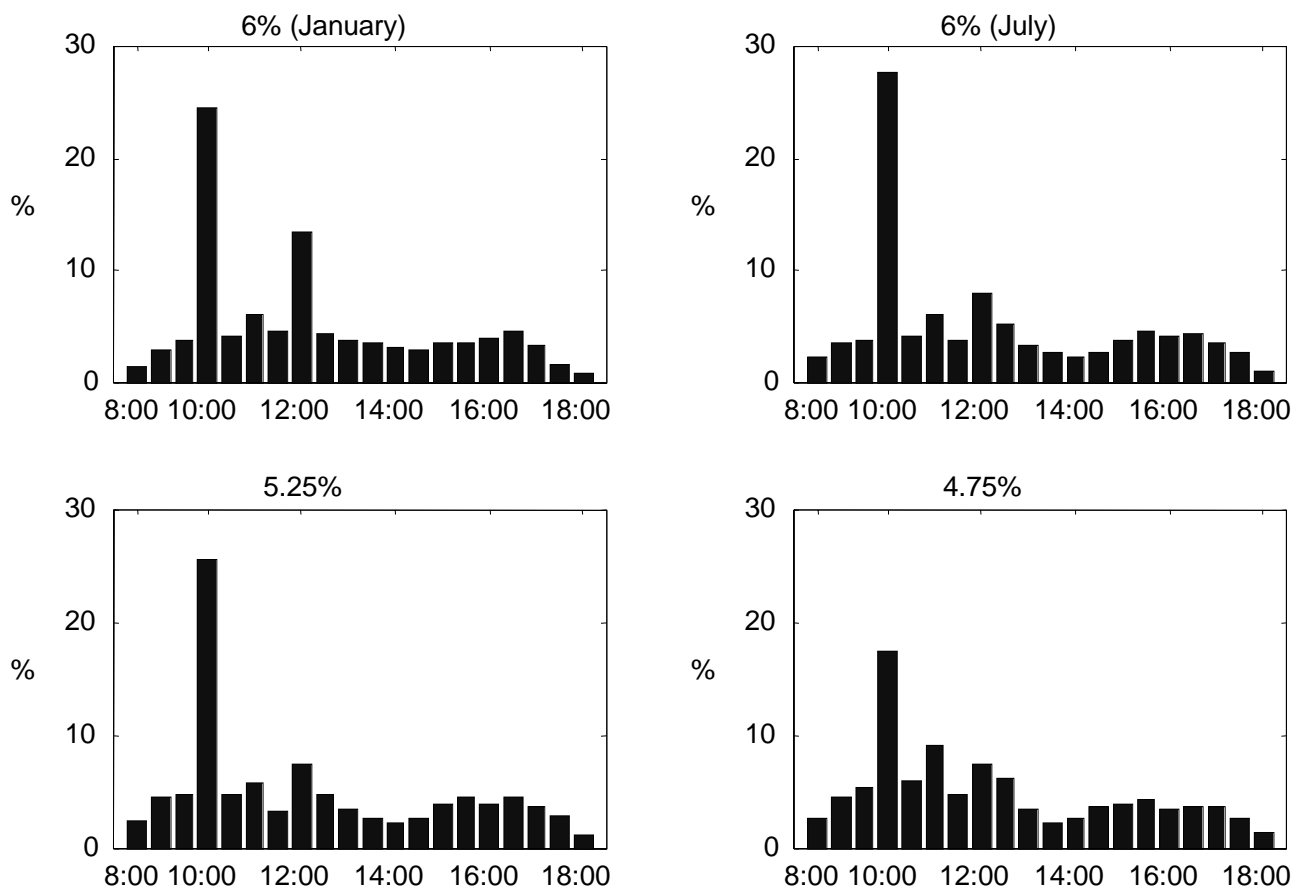
Figure 4 (c)

Intra-day distribution of average trade size
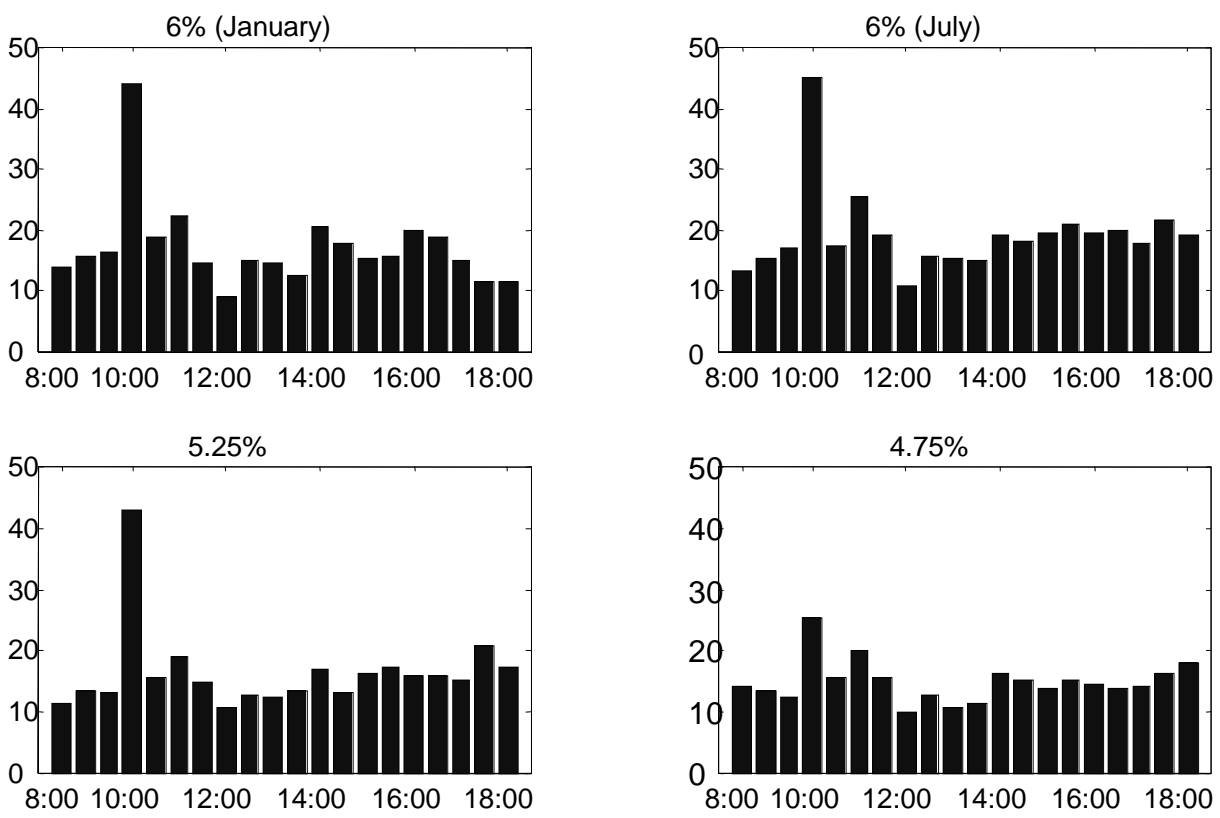

In million DM

\subsection{Construction of equally-spaced time series}

The presence of intra-day patterns of trading activity can induce biases in the measurement of volatility and correlations if we do not ensure that only trades that take place at the same time are compared. For some purposes, I convert the irregularly-spaced transaction series into an equallyspaced time series of prices. How this was done is illustrated in Figure 5. Transactions occur at irregular time intervals at prices $P_{1}, P_{2}$ etc. We lay a grid of fixed time intervals $t=1,2 \ldots T$ over the trading day, and assign to each point of the grid the price of the last available transaction. For example, the price at $t=2, \mathrm{P}_{\mathrm{t}=2}$ becomes $\mathrm{P}_{1}, \mathrm{P}_{\mathrm{t}=3}=\mathrm{P}_{2}$ and $\mathrm{P}_{\mathrm{t}=4}=\mathrm{P}_{4}$. If no transaction occurs during an interval, we still take the last available transaction, thus $\mathrm{P}_{5}=\mathrm{P}_{\mathrm{t}=5}=\mathrm{P}_{4}=\mathrm{P}_{\mathrm{t}=4}$. If there has not been any transaction on the same trading day, eg at $t=1$, then the observation is dropped. This seems preferable to using the closing transaction of the previous day since much more news tends to arrive over night than in any brief trading interval. Observations followed by other transactions within the same time interval, like $\mathrm{P}_{3}$, are discarded.

Figure 5

Construction of an equally spaced time series

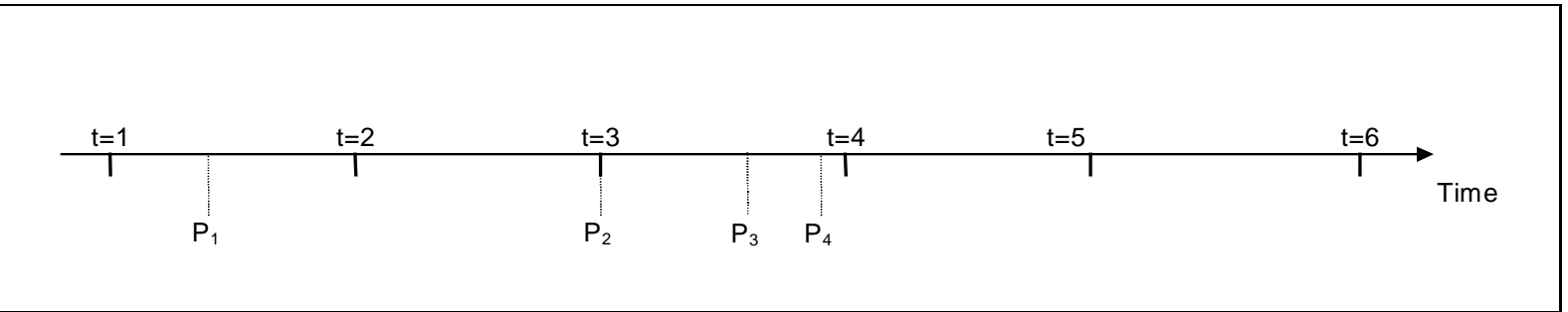

In deciding the length of the fixed intervals, one faces a trade-off between the number of periods without any observations and the amount of observations that are discarded. For the data of this paper, five minute intervals seem a reasonable compromise between the two, although there is some indication that this frequency is too high for days with low trading activity. However, since the focus of 
the analysis are the turbulences during the summer and autumn, when, as we shall see in section 7 , trading activity was particularly large, this seemed less of a problem than loosing information during these periods.

\section{Yields of bunds in 1998}

Figure 6 shows the yields of the four bonds of our sample during $1998 .{ }^{24}$ During the first half of the year, they fell from around $5.3 \%$ at the beginning of January to about $4.8 \%$. The decline accelerated sharply during the second half of July and August. Yields reached their nadir at around $4 \%$ in early October. After a sharp rebounce, they again declined to values of close to $4 \%$ in December. It is interesting to note that the sharp fall in yields began about a month before the Russian default, ie during the first period according to the BIS (1999c) classification presented in section 2.

Figure 6

\section{Yields to maturity}

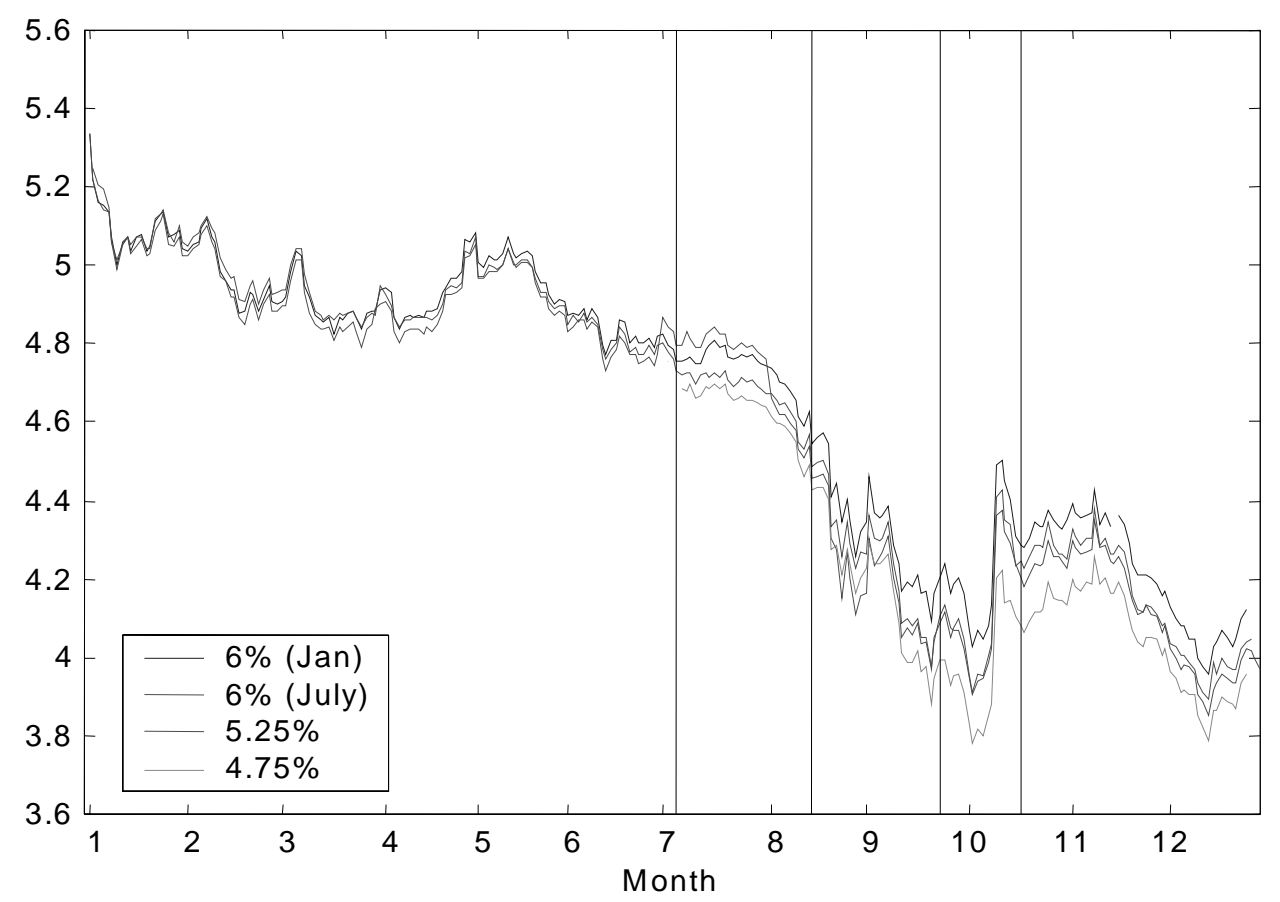

The month of July marked a break not only in the overall movement of yields but also in the pricing relationship between the individual bonds. During the first half of the year, the yields of the three bonds then available moved very closely together, rarely diverging by more than five basis points. In July, the yield spread between the individual securities widened sharply to 12 to 14 basis points between the most recent issue, the $4.75 \%$, and the $6 \%$ (July) issue. ${ }^{25}$ Such a rise in the spread between on-the-run and previous issues seems to have been a quite general phenomenon that also occurred in several other financial markets (BIS [1999c]), and was probably due to the inflow of foreign capital which was invested mainly in the most recent issues.

The yield spread quickly narrowed in August, and even changed sign towards the end of that month. This was probably due to an unusually large open interest in the Bund Future, which aroused fears of a shortage of paper for physical delivery for the September contract. The specification of the Bund

\footnotetext{
24 In order to prevent distortions due to intraday movements in prices or trading activity, the price at 12:00 or last available transaction before was taken. 
Future tends to make it cheaper to deliver a bond with a coupon close to $6 \%$ rather than bonds with lower coupons. If the demand for physical delivery exceeds the amount on the market of the bond that is cheapest to deliver, then some investors have to settle with more expensive paper. This would drive up the price of the cheapest to deliver by an amount determined by the difference in delivery costs. This is precisely what seems to have happened in August of 1998, when investors expected a shortage of the $6 \%$ (July) and expected to have to settle with the $5.25 \%$ or even the $4.75 \%$. When it became apparent in early September that there would be no shortage of the cheapest to deliver because many market participants had closed their open interest, the relationship between the yields quickly reverted to the previous pattern with a positive spread between the most recent and preceding issues. The yield spread between the $6 \%$ (July) and the $4.75 \%$ reached its maximum of 21 basis points on 13 October and then declined to around 10 basis points in November and December. At that time a new Bund had been issued, such that our figures do no longer represent the on-the-run/of-therun spread.

The change in the pricing relationship between the bonds does not extend to high frequencies, though. As can be seen from Table 3, the correlation between the yields of the individual bonds, measured at both the daily and hourly level, did not differ in any economically significant way between the two halves of 1998, although their first differences (ie the daily or hourly changes in the yields) do show a higher correlation during the second half of the year than during the first half.

Table 3

\section{Correlations of yields}

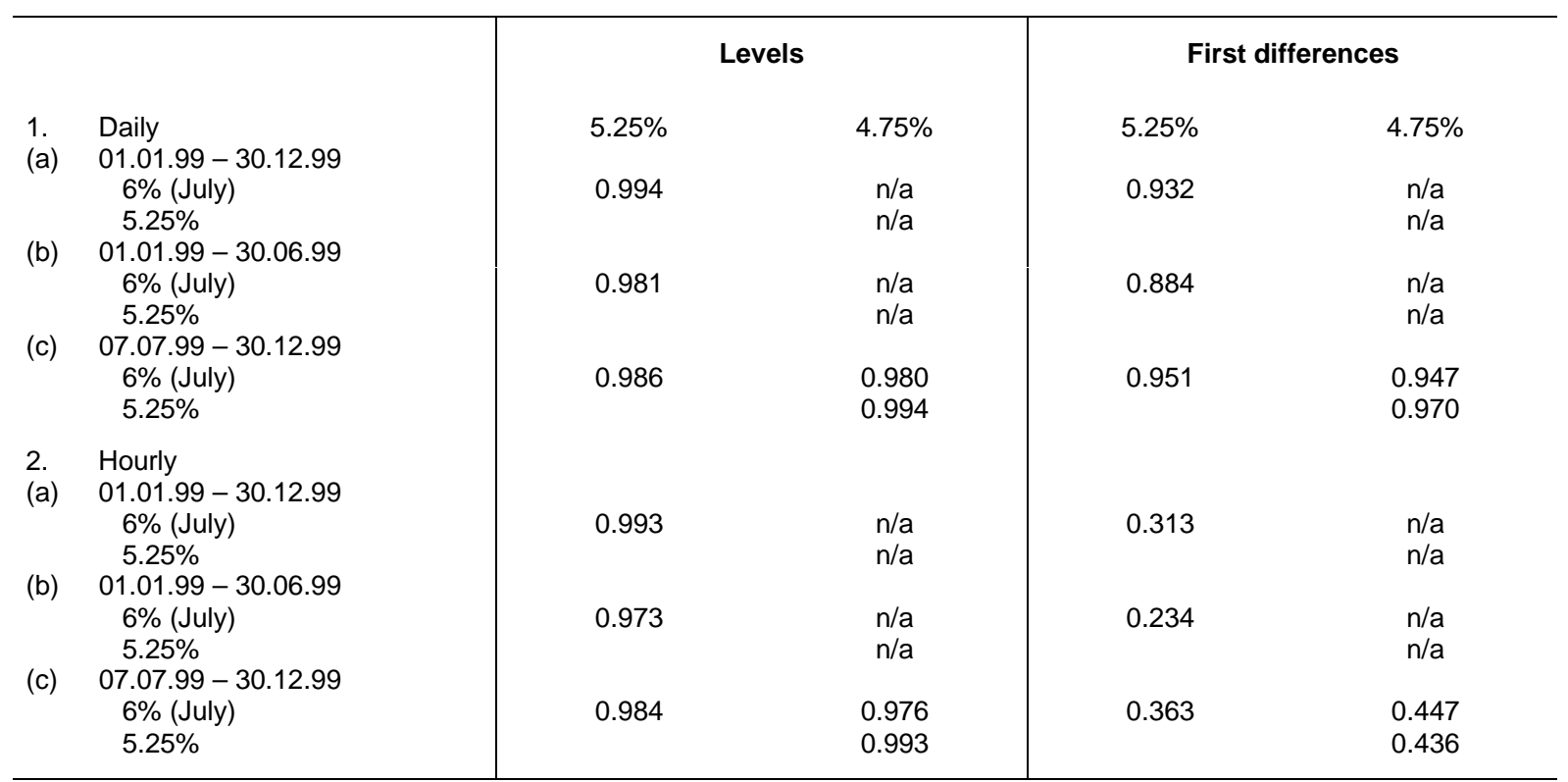

Let us now turn to the volatility of bond yields. Since the expressions "turbulent" and "stress" are almost synonymous for "high volatility", this is what we would expect during the second half of 1998, in particular during the time between the Russian default of 17 August and the US rate cut on 15 October.

We can compute a measure for the price volatility of each stock on each trading day from the equally spaced price series by summing intra-day squared holding returns

$$
\hat{\sigma}_{t}^{2}=\sum_{i}\left(\Delta \log P_{i}\right)^{2} .
$$

Andersen et al (1999) show that this approaches the price volatility of a continuous process as the intervals between the observations goes to zero. The resulting series of volatility intra-day volatility is shown in Figure 7. 
Figure 7

Intra-day volatility of yields in 1998
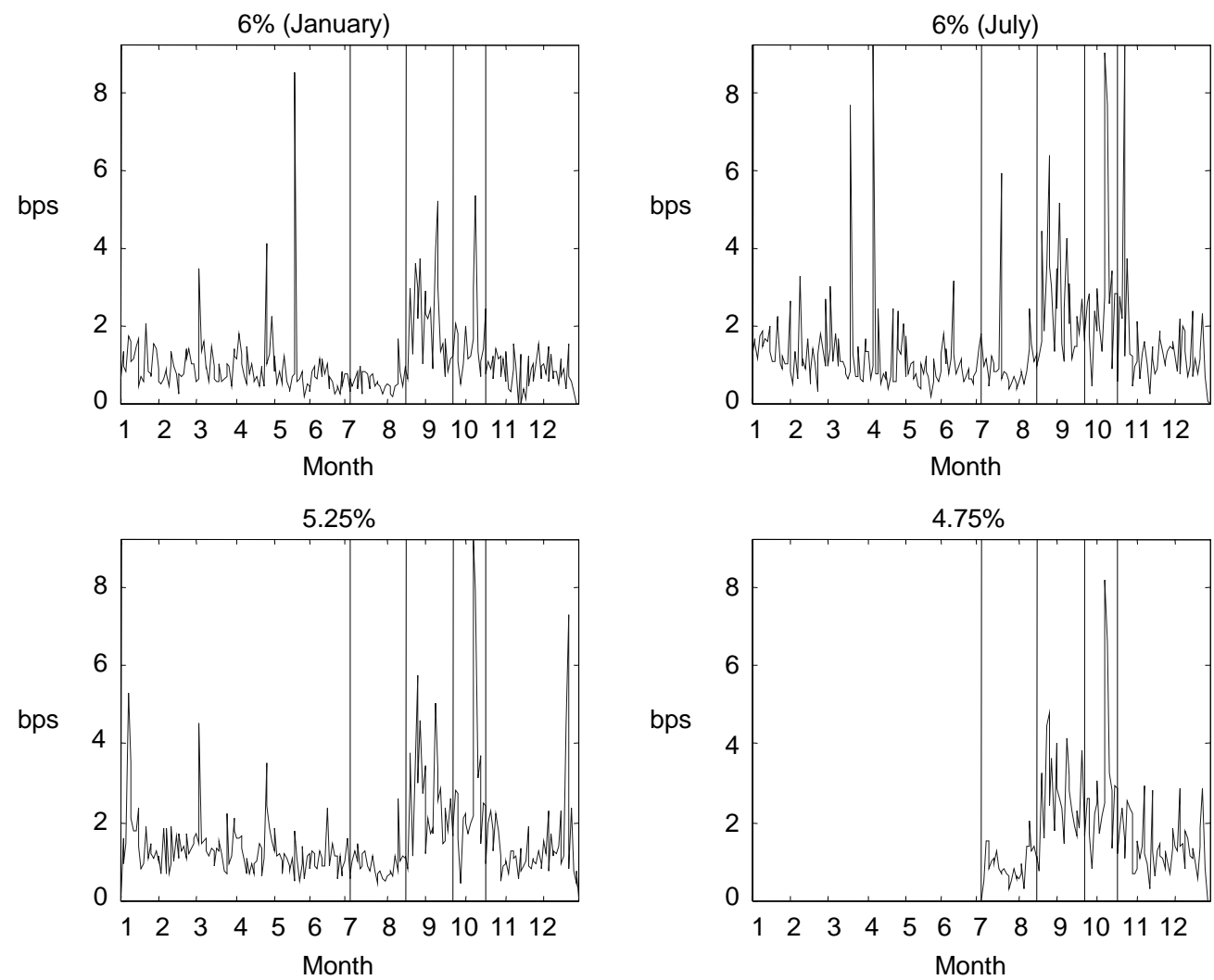

Figure 7 is roughly consistent with what we know from other markets. Volatility remains low during the first period of the turbulences, but soars after the Russian default. Our measure remains high throughout periods II and III, but gradually declines after the US intermeeting rate cut on 15 October, although it remained at around two basis points well above its initial level during most of November and December.

\section{Market liquidity in $\mathbf{1 9 9 8}$}

What were the effects of the capital market turbulences of the summer and autumn of 1998 on the liquidity of the market for German government bonds? Let us begin by looking at activity indicators like the number trades as well as market turnover, before turning to the effective spread as a direct measure for market tightness and depth.

\subsection{Activity indicators}

The daily number of trades and daily turnover, depicted in figures 8 and 9 , decreased somewhat during the first subperiod covering July and part of August relative to the tranquil period, but soared after the Russian default. This coincided with massive inflows of foreign capital into the German bond market of over 30 billion DM per month in July and August, compared to an average of just over 10 billion DM during the first half of 1998. After peaking in late August, activity fell back to normal. Another brief surge in trading took place in the beginning of October, although for some reason this did not affect the $6 \%$ (July) bond. In early November, both the number of trades as well as turnover of the $5.25 \%$ and the $4.75 \%$ dropped due to the introduction of a new bond. 
Figure 8

Daily number of trades in 1998
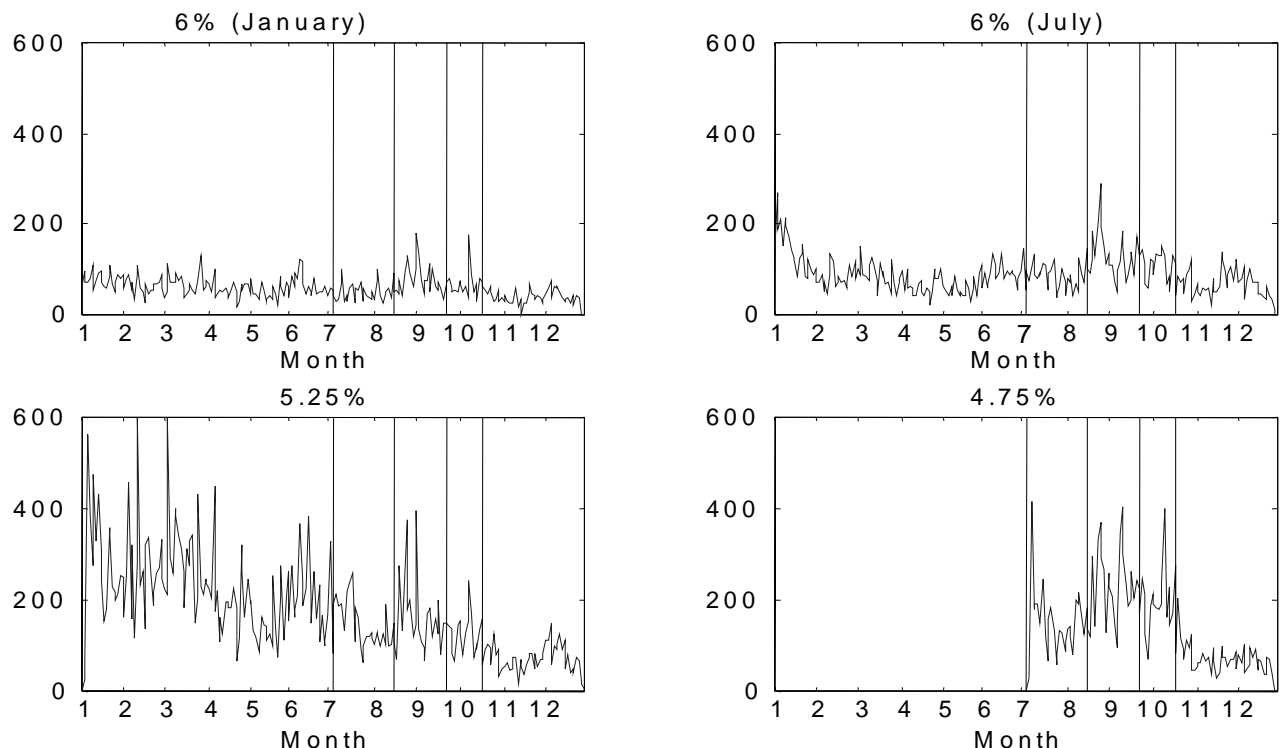

Figure 9

Daily turnover in 1998
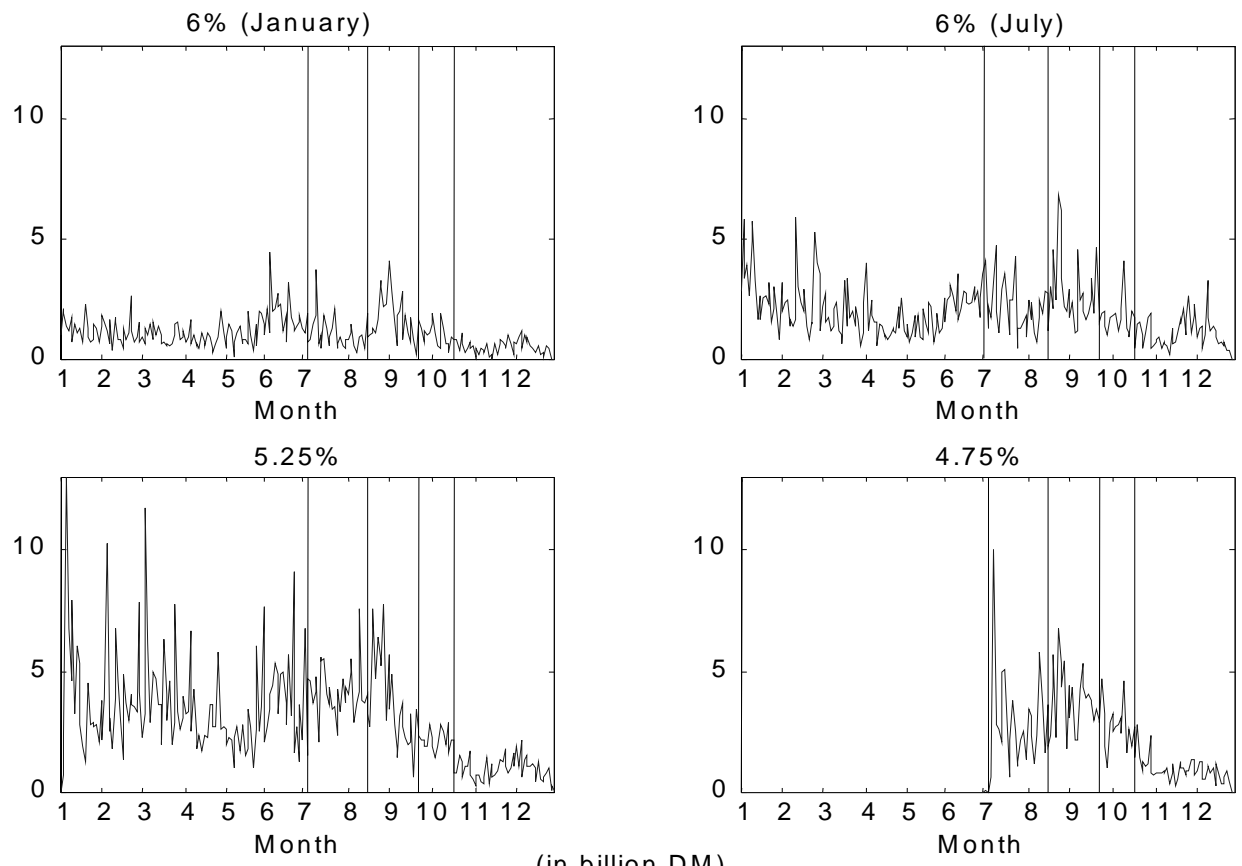

Are the changes in trading activity during the period of turbulence statistically significant? This can be tested by regressing the activity measure, in our case the daily number of trades or daily turnover, on a set of dummy variables that are equal to one in the respective subperiod and zero otherwise. In order to isolate the effects of the turbulences from the effects of a change in the on-the-run issue, I included an further dummy $D_{\text {recent }}$ indicating whether or not the bond was the most recent issue. In order to reduce multicolinearity, $\mathrm{D}_{\text {recent }}$ and the dummies for the first and last period of the turbulences have not been included in the equation for the $4.75 \%$. 
Table 4

Trading activity during the 1998 turbulences

\begin{tabular}{|c|c|c|c|c|c|c|c|c|}
\hline \multirow[b]{2}{*}{ Dep. variable } & \multicolumn{2}{|c|}{ 6\% (Jan.) } & \multicolumn{2}{|c|}{ 6\% (July) } & \multicolumn{2}{|c|}{$5.25 \%$} & \multicolumn{2}{|c|}{$4.75 \%$} \\
\hline & (i) & (ii) & (i) & (ii) & (i) & (ii) & (i) & (ii) \\
\hline $\begin{array}{c}\text { Expl. variables } \\
D_{6.7 .-14.8}\end{array}$ & $\begin{array}{l}-0.00 \\
(-0.01)\end{array}$ & $\begin{array}{l}{ }^{* *}-0.29 \\
(-1.85)\end{array}$ & $\begin{array}{r}{ }^{* * *} 0.38 \\
(3.47)\end{array}$ & $\begin{array}{l}{ }^{* *} 0.29 \\
(2.04)\end{array}$ & $\begin{array}{c}0.16 \\
(0.33)\end{array}$ & $\begin{array}{c}0.52 \\
(0.94)\end{array}$ & - & - \\
\hline $\mathrm{D}_{17.8 .-22-9 .}$ & $\begin{array}{r}* * * 0.61 \\
(4.84)\end{array}$ & $\begin{array}{l}{ }^{* *} 0.35 \\
(1.87)\end{array}$ & $\begin{array}{r}* * * 1.09 \\
(8.37)\end{array}$ & $\begin{array}{r}* * * 0.75 \\
(4.48)\end{array}$ & $\begin{array}{c}0.46 \\
(0.91)\end{array}$ & $\begin{array}{c}0.48 \\
(0.83)\end{array}$ & $\begin{array}{r}* * * 0.93 \\
(8.45)\end{array}$ & $\begin{array}{r}{ }^{\star * *} 0.94 \\
(6.65)\end{array}$ \\
\hline $\mathrm{D}_{23.9 .-15.10}$ & $\begin{array}{r}* * * 0.46 \\
(3.05)\end{array}$ & $\begin{array}{l}{ }^{*}-0.333 \\
(-1.46)\end{array}$ & $\begin{array}{r}* * * 0.96 \\
(6.08)\end{array}$ & $\begin{array}{l}* 0.29 \\
(1.38)\end{array}$ & $\begin{array}{c}0.37 \\
(0.73)\end{array}$ & $\begin{array}{c}0.05 \\
(0.09)\end{array}$ & $\begin{array}{r}* * * 0.68 \\
(5.12)\end{array}$ & $\begin{array}{r}{ }^{* * *} 0.50 \\
(2.94)\end{array}$ \\
\hline $\mathrm{D}_{16.10 .-31.12}$ & $\begin{array}{c}0.07 \\
(0.42)\end{array}$ & $\begin{array}{r}{ }^{* * *}-0.92 \\
(-3.83)\end{array}$ & $\begin{array}{r}* * * 0.69 \\
(4.13)\end{array}$ & $\begin{array}{c}0.07 \\
(0.30)\end{array}$ & $\begin{array}{c}0.28 \\
(0.54)\end{array}$ & $\begin{array}{l}-0.22 \\
(-0.37)\end{array}$ & - & - \\
\hline $\mathrm{D}_{\text {recent }}$ & - & - & $\begin{array}{c}0.25 \\
(0.63)\end{array}$ & $\begin{array}{c}0.15 \\
(0.28)\end{array}$ & $\begin{array}{c}0.16 \\
(0.33)\end{array}$ & $\begin{array}{c}0.11 \\
(0.20)\end{array}$ & - & - \\
\hline \# observations & 250 & 250 & 250 & 250 & 249 & 249 & 124 & 124 \\
\hline
\end{tabular}

Dependent variable: (i) daily number of trades, (ii) daily turnover, normalised by their mean. T-values in brackets. Dummies equal to 1 during indicated period and zero otherwise, dummy recent one if on-the-run and zero otherwise. Explanatory variables also include a constant and time trend. Newey-West correction for autocorrelation and heteroscedasticity. Significant on ${ }^{*} 90 \%,{ }^{* *} 95 \%$, ${ }^{* *} 99 \%$ confidence level

The results of the regressions are displayed in Table 4. They indicate that the surge in both the number of trades and in turnover during the second period of the turbulences is statistically highly significant. The only exception to this is the $5.25 \%$ bond, where none of the dummies, including , $\mathrm{D}_{\text {recent, }}$, proved to be significant. There is also some indication that the number of trades, although not in all cases turnover, was higher during the third period than on average. The individual bonds behaved quite differently during the initial and final periods of the turbulences, when some of them became more actively traded and the others less so.

The results indicate that markets have been sufficiently liquid to sustain a larger than normal number of trades and turnover, but this does not necessarily imply that market liquidity remained unaffected. It is therefore necessary to look at direct indicator for market liquidity and not solely rely on activity indicators like the number of trades of turnover.

\subsection{Effective spreads}

Let us now turn to a measure of liquidity that is directly related to both the tightness and the depth of the market, the effective spread measured by Roll's statistic. Before proceeding, a word of caution is needed. The Roll measure is likely to underestimates the "true" spread in the presence of inventory control or adverse selection effects. Since these are more likely to occur in times of market stress (when prices are more volatile, adding to inventory costs, and there is more scope for private information), our results are liable to underestimate any worsening in market liquidity.

Table 5 shows the Roll measures for the effective spread estimated from transactions prices. The spreads appear to have been very low, and consequently the market very liquid, during the first subperiod of the turbulences ranging from the beginning of July to the eve of the Russian default a month and half later. After the Russian default, effective spreads increase to 1.73 to 1.9 basis points, although they remain below their level of the first half of the year for the two $6 \%$ bonds. They rise further after the LTCM rescue, to more than 2 basis points. The only exception is the $6 \%$ (January) bond, whose effective spread declines to 1.3 basis points. The spreads ease during the fourth and final subperiod to levels near or even below that of the first half of the year. It is possible that the odd result of a very high spread for this bond during the period of tranquillity is due to data problems. 
Table 5

Effective bid-ask spreads (Roll measure, in basis points)

\begin{tabular}{|c|c|c|c|c|}
\hline Period & 6\% (January) & 6\% (July) & $5.25 \%$ & $4.75 \%$ \\
\hline 2 Jan - 3 July & 2.60 & 1.95 & 1.13 & $\mathrm{n} / \mathrm{a}$ \\
\hline 6 July - 14 Aug & 0.58 & 1.54 & 0.78 & 1.18 \\
\hline 17 Aug - 22 Sept & 1.90 & 1.88 & 1.80 & 1.73 \\
\hline 23 Sept - 15 Oct & 1.28 & 2.51 & 2.09 & 2.02 \\
\hline $16 \mathrm{Oct}-31 \mathrm{Dec}$ & 0.82 & 1.48 & 1.21 & 1.11 \\
\hline
\end{tabular}

The estimation of effective spreads over prolonged periods of time has the advantage that one does not have to worry about having too few observations, but their results may mask important developments during these periods. I therefore complement the analysis from Table 5 by estimating the Roll measure for each trading day of the year. In order to reduce the small sample bias associated with this measure, I only consider days with more than 50 trades, which explains the gaps in the graphs, mainly for the two $6 \%$ bonds, which also show a lot of noise.

Figure 10

\section{Effective spreads (Roll measure) in 1998}
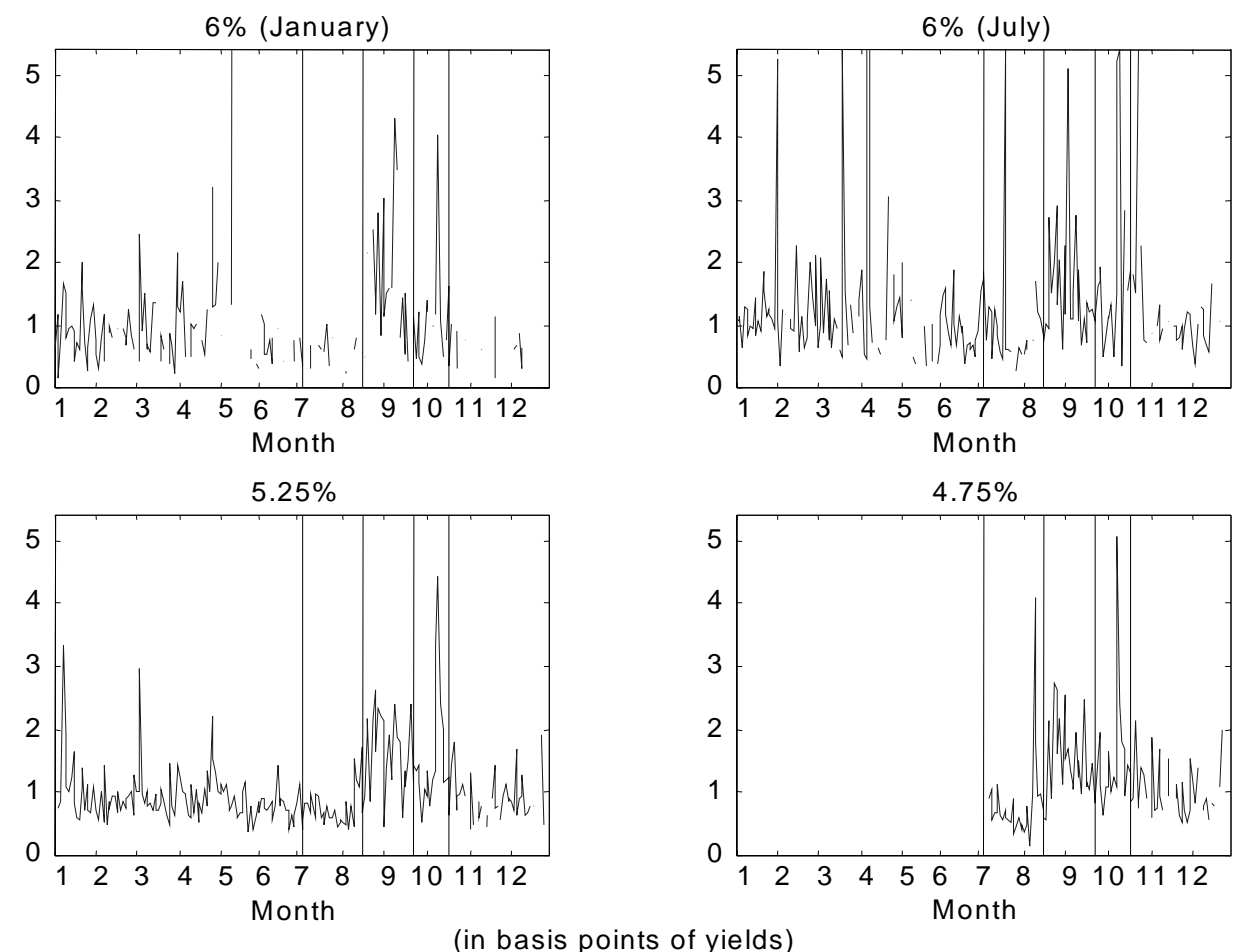

The daily spreads reproduced in Figure 10 broadly confirm the picture obtained from Table 5 . Effective spreads for the $5.25 \%$ bond fluctuated around one basis point during the first half of the year and fell somewhat during July and early August. During the second half of August, they soared to values of more than two basis points but eased somewhat during September. A dramatic increase occurred around 8 and 9 October, when the spread for the $5.25 \%$ reached 4.4 and those of the $4.75 \%$ and the $6 \%$ July bonds broke through the 5 basis point barrier. Afterwards, effective spreads quickly declined to around 1.5 basis points in November and December. 
We can repeat the exercise of the previous section and test whether the changes in spreads are statistically significant. Since changes in the effective spread may be due to variations in order size, I include the daily average trade size as additional explanatory variable. The results are presented in Table 6.

Table 6

Daily effective spreads during the 1998 turbulences

\begin{tabular}{|c|c|c|c|c|}
\hline & $6 \%$ (Jan.) & 6\% (July) & $5.25 \%$ & $4.75 \%$ \\
\hline $\begin{array}{c}\text { Expl. variables } \\
D_{6.7 .-14.8}\end{array}$ & $\begin{array}{c}{ }^{* *}-1.294 \\
(-1.77)\end{array}$ & $\begin{array}{l}0.114 \\
(0.31)\end{array}$ & $\begin{array}{l}-0.206 \\
(-0.44)\end{array}$ & - \\
\hline $\mathrm{D}_{17.8 .-22-9 .}$ & $\begin{array}{l}-0.664 \\
(-0.88)\end{array}$ & $\begin{array}{l}{ }^{*} 0.584 \\
(1.35)\end{array}$ & $\begin{array}{l}{ }^{*} 0.754 \\
(1.54)\end{array}$ & $\begin{array}{r}{ }^{* * *} 0.461 \\
(3.51)\end{array}$ \\
\hline$D_{23.9 .15 .10}$ & $\begin{array}{l}-1.069 \\
(-1.17)\end{array}$ & $\begin{array}{l}{ }^{* *} 0.935 \\
(1.73)\end{array}$ & $\begin{array}{l}{ }^{*} 0.800 \\
(1.59)\end{array}$ & $\begin{array}{c}* * * 0.530 \\
(3.39)\end{array}$ \\
\hline$D_{16.10 .-31.12}$ & $\begin{array}{l}*-1.531 \\
(-1.44)\end{array}$ & $\begin{array}{l}0.635 \\
(1.08)\end{array}$ & $\begin{array}{c}0.249 \\
(0.49)\end{array}$ & - \\
\hline $\mathrm{D}_{\text {recent }}$ & - & $\begin{array}{l}-0.293 \\
(-0.24)\end{array}$ & $\begin{array}{l}-0.165 \\
(-0.35)\end{array}$ & - \\
\hline Av. trade size & $\begin{array}{l}{ }^{*} 0.522 \\
(1.33)\end{array}$ & $\begin{array}{l}{ }^{* *} 0.447 \\
(1.73)\end{array}$ & $\begin{array}{l}0.065 \\
(0.70)\end{array}$ & $\begin{array}{l}-0.010 \\
(-0.05)\end{array}$ \\
\hline \# observations & 250 & 250 & 249 & 124 \\
\hline
\end{tabular}

Dependent variable: Roll measure for the effective spread, normalised by their mean. T-values in brackets. Dummies equal to 1 during indicated period and zero otherwise, dummy recent one if on-the-run and zero otherwise. Explanatory variables also include a constant and time trend. Newey-West correction for autocorrelation and heteroscedasticity. Significant on ${ }^{*} 90 \%,{ }^{* *} 95 \%$, ${ }^{* *} 99 \%$ confidence level.

The coefficients of the dummies for the second and third periods of the turbulences are significantly positive for three of the four bonds. This indicates that liquidity had indeed worsened after the Russian default and only recovered with the inter-meeting rate cut of the Fed. We find no evidence for higher effective spreads either in the run-up period between 6 July and 14 August or the cooling-down period after 16 October. The results obtained for the $6 \%$ (January) bond do not contradict this picture but are consequence of a relatively high spread during the first half of the year.

We can test for the importance of the adverse selection component of the spread by running a regression of the effective spreads on expected and unexpected trading volume (Bessembinder [1994], Hartmann [1999]). Unpredictable volume should mainly be due to the arrival of information, which increases the scope for adverse selection problems, and should therefore be positively related to the spread. A surge in predictable volume, in contrast, permits market makers to take advantage of scale economies and hence reduce spreads. In addition, a rise in expected volume that goes hand in hand with a larger number of orders (rather than an increase in order size) reduces the risk of inventory imbalances due to the law of large numbers.

I estimate the following equation:

$S_{i t}=\beta_{i 0}+\beta_{i 1}$ evol $_{i t}+\beta_{i 2}$ uvol $_{i t}+\beta_{i 3}$ evola $_{i t}+\varepsilon_{i t}$,

where expected volume evol $l_{i t}$ of bond $i$ is proxied with the (in-sample) fitted values from a standard ARMA model, ${ }^{26}$ and unexpected volume $u \mathrm{vol}_{i t}$ with the corresponding residuals. In order to control for variations in the inventory holding costs, I control for the expected price volatility evola $a_{i t}$, also obtained from an ARMA model. Since unexpected volume may be determined by the bid-ask spread, we face a problem of endogeneity that could induce a bias in our estimation results (Hartmann [1999]). Unfortunately, our dataset does not contain any variable that is exogenous and could be used as an

26 The prefered specification was an ARMA $(1,1)$ model. Dummies for weekday effects turned out not to be significant. 
instrument for $\mathrm{uvol}_{i t}{ }^{27}$ We therefore have to live with the endogeneity problem, although we have to interpret the results in light of the possible bias. The results of the estimation are displayed in Table 7.

\section{Table 7}

\section{Effective spreads and trading volume}

\begin{tabular}{|c|c|c|c|}
\hline & 6\% (July) & $5.25 \%$ & $4.75 \%$ \\
\hline $\begin{array}{l}\text { Expl. Variables } \\
\text { Exp. volume }\end{array}$ & $\begin{array}{l}0.202 \\
(0.87)\end{array}$ & $\begin{array}{l}{ }^{*} 0.164 \\
(1.89)\end{array}$ & $\begin{array}{l}0.103 \\
(0.92)\end{array}$ \\
\hline Unexp. volume & $\begin{array}{l}0.201 \\
(0.52)\end{array}$ & $\begin{array}{c}* * * 0.524 \\
(3.72)\end{array}$ & $\begin{array}{r}{ }^{* * *} 0.659 \\
(4.12)\end{array}$ \\
\hline Exp. volatility & $\begin{array}{c}{ }^{* *} 0.349 \\
(2.44)\end{array}$ & $\begin{array}{c}{ }^{* \star *} 0.555 \\
(7.78)\end{array}$ & $\begin{array}{r}{ }^{\star \star *} 0.337 \\
(4.36)\end{array}$ \\
\hline$R^{2}$ & 0.06 & 0.46 & 0.25 \\
\hline \# observations & 124 & 137 & 109 \\
\hline F-Test: $\mathrm{H}_{0}: \beta_{1}=\beta_{2}$ & - & **5.4 & $* * * 11.4$ \\
\hline
\end{tabular}

Sample: 27 May - 30 December, 1998, except for the 4.75\%, which started on 6 July. Dependent variable: Roll measure for the effective spread, normalised by their mean. T-values in brackets. Volume: Total volume of all deliverable bonds. Expected Volume: 1-step out-of-sample forecasts from ARMA-model. Unexpected Volume=Volume-Expected Volume. Explanatory variables also include a constant. Newey-West correction for autocorrelation and heteroscedasticity. Significant on ${ }^{*} 90 \%,{ }^{* *} 95 \%,{ }^{* *} 99 \%$ confidence level.

The relationship between unexpected volume and effective spreads is positive and highly significant for the $5.25 \%$ and the $4.75 \%$ bonds, which is in line with our hypothesis. The fact that the relevant coefficient is not significant for the $6 \%$ (July) bond may be due to the inordinate amount of noise in the series for the spread. The coefficients on expected volume are positive, but either insignificant or only weakly significant, which indicates that there do not seem to be much economies to scale in market making. The importance of inventory holding costs is shown by the highly significant and positive coefficient for expected volatility. We can reject the hypothesis that the coefficients of our two volume measures are equal for two of the bonds, which is in accordance with the results obtained for the forex market (see Hartmann [1999] and references therein). since our data only contains information on transactions. 
Figure 11

Unexpected volume and effective spreads
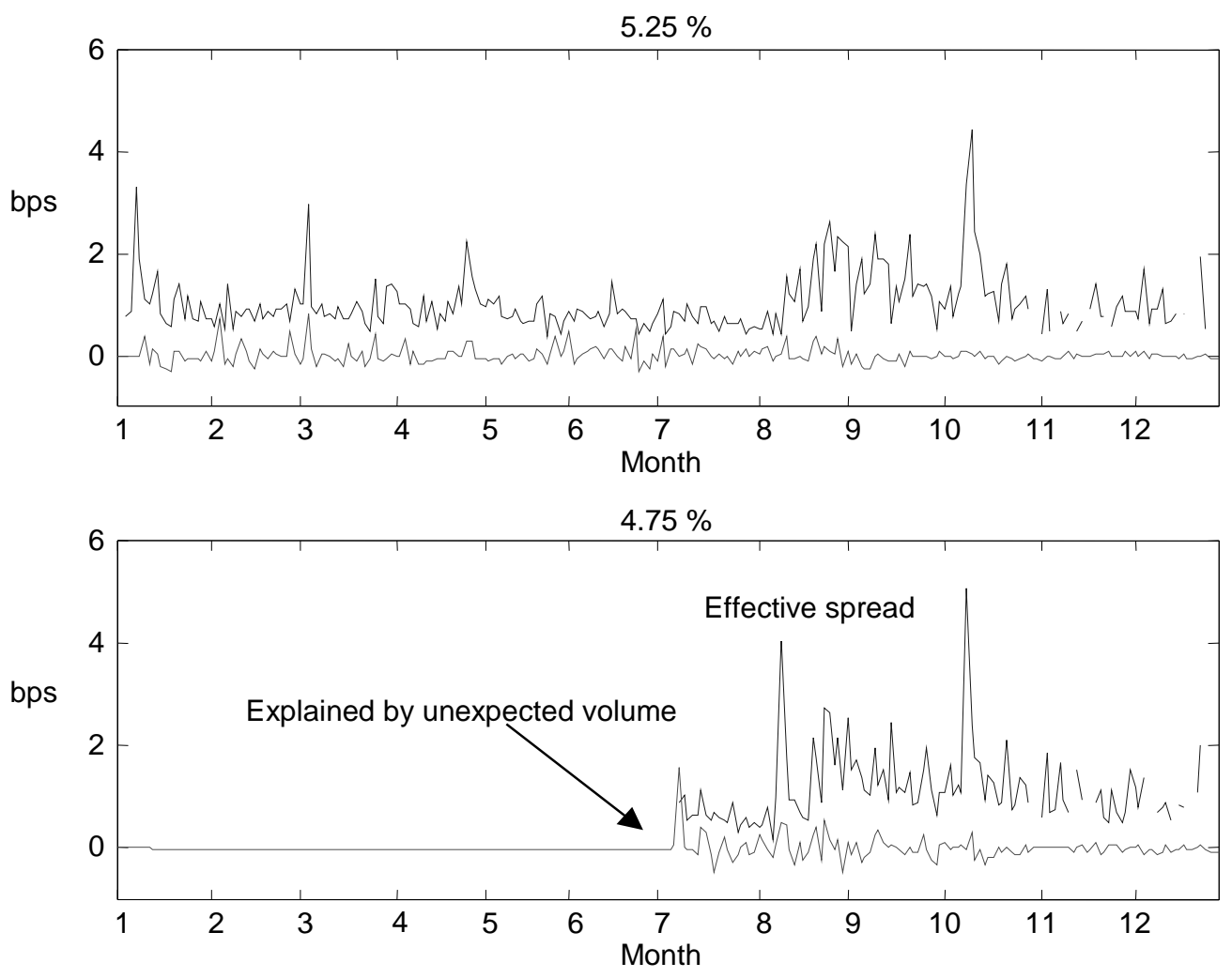

The strong statistical relationship between unexpected volume and bid-ask spreads cannot explain the rise in the latter that occured from August to October. Figure 11 plots the spreads and the proportion that can be explained by unexpected volume $\left(\beta_{i 2} u v V_{i t}\right)$. Spreads seem to be related to surprises in volume only in the very short run (a day) but not over prolonged periods of time. When the effective bid-ask spreads surged after the Russian devaluation and later during the uncertainty about the yencarry-trades, unexpected volume remained essentially flat. This is not consistent with the hypothesis that the fear of adverse selection caused market makers to widen their spreads.

\subsection{Did banks destabilise the market?}

More generally, did market makers on average play a stabilising or a destabilising role during the turbulences? In particular, did they buy when prices were falling and sell when they were rising, or was it the other way around? We explore this question by regressing the changes in inventory associated with each transaction on the first difference in yields as well as on dummies equal to one during each of the turbulent subperiods and zero otherwise, multiplied by the yield change. A negative coefficient would indicate that banks were selling into the falling market or buying when prices were increasing. Since inter-dealer trades do not have any effect on the inventory of the aggregate banking sector we omit them and confine our analysis to client trades only. 
Table 8

Changes in inventories and prices

\begin{tabular}{|c|c|c|c|c|}
\hline & $6 \%$ (January) & 6\% (July) & $5.25 \%$ & $4.75 \%$ \\
\hline$\Delta$ yields & $\begin{array}{l}-0.008 \\
(-0.11)\end{array}$ & $\begin{array}{c}0.036 \\
(0.47)\end{array}$ & $\begin{array}{c}0.042 \\
(0.77)\end{array}$ & $\begin{array}{c}0.098 \\
(0.69)\end{array}$ \\
\hline $\mathrm{D}_{\text {6.7.-14.8. }} \times \Delta$ yields & $\begin{array}{l}0.058 \\
(0.03)\end{array}$ & $\begin{array}{c}0.017 \\
(0.05)\end{array}$ & $\begin{array}{l}0.002 \\
(0.01)\end{array}$ & - \\
\hline $\mathrm{D}_{17.8 .-22-9 .} \times \Delta$ yields & $\begin{array}{c}0.026 \\
(0.11)\end{array}$ & $\begin{array}{l}-0.107 \\
(-0.70)\end{array}$ & $\begin{array}{l}-0.004 \\
(-0.04)\end{array}$ & $\begin{array}{l}-0.095 \\
(-0.53)\end{array}$ \\
\hline $\mathrm{D}_{23.9 .-15.10 . .} \times \Delta$ yields & $\begin{array}{r}0.001 \\
(0.00)\end{array}$ & $\begin{array}{c}0.021 \\
(0.096)\end{array}$ & $\begin{array}{c}-0.29 \\
(-0.27)\end{array}$ & $\begin{array}{l}-0.038 \\
(-0.20)\end{array}$ \\
\hline $\mathrm{D}_{16.10 .31 .12 .} \times \Delta$ yields & $\begin{array}{c}-0.096 \\
(-0.12)\end{array}$ & $\begin{array}{c}0.016 \\
(0.08)\end{array}$ & $\begin{array}{c}-0.054 \\
(-0.34)\end{array}$ & - \\
\hline \# observations & 7,853 & 9,266 & 20,111 & 8,035 \\
\hline
\end{tabular}

Client transactions only. Regression of changes in inventories on a constant and changes in yields. Variables standardised by dividing through standard deviation. T-values in brackets. Newey-West correction for autocorrelation and heteroscedasticity. Significant on * $90 \%$, ${ }^{* *} 95 \%$ confidence level

The results reproduced in Table 8 give no evidence on a correlation between changes in inventory and the first difference in prices. This indicates that market makers did not exacerbate price fluctuations by selling into falling markets or buying when prices were rising. On the other hand, they did not, on average, stabilise by behaving anticyclically. This is not really surprising given the small size of the inventory at most times.

\section{Conclusions}

The paper examines the liquidity of the secondary market for four German benchmark government bonds during the financial market turbulences in the summer and autumn of 1998. The analysis is based on a unique dataset provided by the German securities regulator, which covers every single transaction in these bonds in Germany.

The empirical findings of the paper can be summarised as follows:

The intra-day volatility of yields more than doubled in the wake of the Russian devaluation on 17 August and experienced a further peak on 8 and 9 October.

The yield spread between the individual bonds of our sample soared from less than five basis points during the first half of the year to more than twenty basis points in early October. No equivalent breakdown in the pricing relationship can be found at daily or hourly level, however. This indicates that the bonds remained close substitutes for hedging purposes even during periods of stress.

The surge in volatility and the building up of the yield spread occurred at a time of heavy trading activity. For three of the four bonds, both the number of trades and daily turnover were statistically significantly higher between 17 August and 15 October than during the first half of the year.

The effective bid-ask spreads (measured by Roll's [1984] approach) on the two most heavily traded bonds increased from just over one basis point to 1.8 basis points after the Russian de-facto default on 17 August, and rose above two basis points after the LTCM rescue operation. They peaked around 8 and 9 October at around five basis points. This rise is statistically significant even after controlling for changes in the average transaction size.

Effective bid-ask spreads are positively related to unexpected trading volume, which should reflect the amount of private information in the market. Nevertheless, surprises volume cannot explain the surge in spreads that occurred during the turbulences.

How does this answer our initial question on "how did the "safe-haven" weather the storm"? The finding that the effective spread increased considerably during the turbulences clearly indicates that the market suffered from a reduction in liquidity. This result is even more clear cut if we consider that our estimates for the effective spread based on the Roll [1984] measure are downward biased in the 
presence of inventory control and adverse selection effects, which are likely to be important particularly in times of great volatility.

Nevertheless, while agents may have faced a higher cost of trading, they were still able to trade. Our data does not tell us whether individual agents were able to turn over their position as quickly as they would have liked, but the fact that the market has been able to sustain a significantly higher than normal number of trades and volume suggests that such problems were not widespread, if they occurred at all. In this sense, liquidity provision has been remarkably effective in dealing with the turbulences, especially when seen in contrast to what happened in the US bond market.

Apart from the issue of financial stability, I mentioned two other reasons for why a central bank should monitor the liquidity in the secondary market for government bonds: the quality of indicators and the borrowing costs of government. Indicator quality clearly suffers if it becomes more costly to trade. Hence our findings provide further evidence for the already widely known fact that indicators are the least likely to be accurate at times when they are most needed.

The present paper considers only a small, albeit important, segment of the market. It would be interesting to extend the analysis to a) the futures market, which is far more active than the spot market, and b) bonds from other issuers. It would also be of interest to compute a measure of liquidity that is more robust to the presence of inventory control and adverse selection effects than the Roll measure. Both extensions are left for future work.

\section{References}

Amihud, Y \& H Mendelson (1991): "Liquidity, Maturity and the Yields on U.S. Treasury Securities", Journal of Finance, 66: 1411-25

Andersen, T G, T Bollerslev, F X Diebold \& P Labys (1999): "The Distribution of Exchange Rate Volatility", NBER Working Paper 6961

Bagehot, W [pseud.] (1971): "The Only Game in Town", Financial Analysts Journal, 27: 12-4

Bank for International Settlements (1999a): "International Banking and Financial Markets Developments", BIS Quarterly Review, March

Bank for International Settlements (1999b): Market Liquidity: Research Findings and Selected Policy Implications, Report of a Study Group established by the Committee on the Global Financial System of the central banks of the Group of Ten countries, May

Bank for International Settlements (1999c): A Review of Financial Market Events in Autumn 1998, Committee on the Global Financial System , October

Bessembinder, H (1994): "Bid-Ask Spreads in the Interbank Foreing Exchange Markets", Journal of Financial Economics, 35: 317-48

Brady, N (1989): Report of the Presidential Task Force on Market Mechanisms, January, Washington, DC: Government Printing Office Choi, J Y, D Salandro \& K Shastri (1988) "On the Estimation of BidAsk Spreads: Theory and Evidence", Journal of Financial and Quantitative Analysis, 23(2): 245-69

Davis, E P (1999): "A Reappraisal of Market Liquidity Risk in the Light of the Russia/LTCM Global Securities Market Crisis", Paper presented to the workshop on "Empirical Research on bank supervision and Structure", Bank for International Settlements, June 1999

Deutsche Bundesbank (1998): Monthly Report, December

Glosten, L \& P Milgrom (1985): "Bid, Ask, and Transaction Prices in a Specialist Market with Heterogeneously Informed Traders", Journal of Financial Economics, 13: 71-100

Hartmann, P (1999): "Trading Volumes and Transaction Costs in the Foreign Exchange Market: Evidence from Daily Dollar-Yen Spot Data", Journal of Banking and Finance, 23: 801-24

Hasbrouck, J (1991): "Measuring the Information Content of Stock Trades", Journal of Finance, 46: 178-208

Ho, T \& H R Stoll (1981): "Optimal Dealer Pricing under Transactions and Return Uncertainty", Journal of Financial Economics, 9: 47-73 
Ho, T \& H Stoll (1983): "The Dynamics of Dealer Markets under Competition”, Journal of Finance, 38: 1053-74

Huang, R D \& H R Stoll (1997): "The Components of the Bid-Ask Spread: A General Approach", Review of Financial Studies, 10(4):

International Monetary Fund (1998): World Economic Outlook and International Capital Markets Interim Assessment, December

Kyle, A S (1985): "Continuous Auctions and Insider Trading", Econometrica, 53(6): 1315-35

Longstaff, F A (1995): "How Much Can Marketability Affect Security Values?", Journal of Finance, 50(5): 1767-74

Madhavan, A (1992): "Trading Mechanisms in Securities Markets", Journal of Finance, 47: 607-42

O'Hara, M (1995): Market Microstructure Theory, Cambridge MA \& Oxford: Blackwell

O'Hara, M \& G Oldfield (1986): "The Microeconomics of Market Marking", Journal of Financial and Quantitative Analysis, 21, December: 361-76

Proudman, J (1995): "The Microstructure of the UK Gilt Market", Bank of England, Working Paper 38

Roll, R (1984): "A Simple Implicit Measure of the Effective Bid-Ask Spread in an Efficient Market", Journal of Finance, 39: 1127-40

Stoll, H R (1989): "Inferring the Components of the Bid-Ask Spread: Theory and Empirical Tests", Journal of Finance, 44(1): 115-34

Vitale, $P$ (1998): "Two Months in the Life of Several Gilt-Edged Market Makers on the London Stock Exchange", Journal of International Financial Markets, Institutions and Money, 8: 299-324 